\title{
Accounting Transparency and the Term Structure of Credit Default Swap Spreads
}

Bajlum, Claus; Tind Larsen, Peter

Document Version

Final published version

Publication date:

2007

License

CC BY-NC-ND

Citation for published version (APA):

Bajlum, C., \& Tind Larsen, P. (2007). Accounting Transparency and the Term Structure of Credit Default Swap Spreads. Aarhus Universitetsforlag.

Link to publication in CBS Research Portal

\section{General rights}

Copyright and moral rights for the publications made accessible in the public portal are retained by the authors and/or other copyright owners and it is a condition of accessing publications that users recognise and abide by the legal requirements associated with these rights.

\section{Take down policy}

If you believe that this document breaches copyright please contact us (research.lib@cbs.dk) providing details, and we will remove access to the work immediately and investigate your claim.

Download date: 26. Apr. 2023 


\title{
Accounting Transparency and the Term Structure of Credit Default Swap Spreads*
}

\author{
Claus Bajlum ${ }^{\dagger} \quad$ Peter Tind Larsen ${ }^{\ddagger}$ \\ Current Version: August 7, 2007 \\ First Draft: June 15, 2007
}

\begin{abstract}
This paper estimates the impact of accounting transparency on the term structure of CDS spreads for a large cross-section of firms. Using a newly developed measure of accounting transparency in Berger, Chen \& Li (2006), we find a downward-sloping term structure of transparency spreads. Estimating the gap between the high and low transparency credit curves at the 1, 3, 5, 7 and 10-year maturity, the transparency spread is insignificant in the long end but highly significant and robust at 20 bps at the 1-year maturity. Furthermore, the effect of accounting transparency on the term structure of CDS spreads is largest for the most risky firms. These results are strongly supportive of the model by Duffie \& Lando (2001), and add an explanation to the underprediction of short-term credit spreads by traditional structural credit risk models.
\end{abstract}

${ }^{*}$ We thank Lombard Risk for access to the credit default swap data. We thank Christian Riis Flor, Peter Løchte Jørgensen, David Lando, Mads Stenbo Nielsen, Thomas Plenborg and participants at the Danish Doctoral School of Finance Workshop 2007 for valuable comments and insights. Any remaining errors are our own.

${ }^{\dagger}$ Danmarks Nationalbank and Copenhagen Business School, Department of Finance, Solbjerg Plads, 2000 Frederiksberg, Denmark. E-mail: cb.fi@cbs.dk, tel.: +45 38153579.

${ }^{\ddagger}$ School of Economics and Management, University of Aarhus, Universitetsparken 1322, 8000 Aarhus C, Denmark. E-mail: plarsen@econ.au.dk, tel.: +45 89422139. 


\section{Introduction}

Traditional structural credit risk models originating with Black \& Scholes (1973) and Merton (1974) define default as the first passage of a perfectly measured asset value to a default barrier. While later extensions that allow for endogenous default and debt renegotiations have increased predicted spread levels, it is well-known in the empirical literature that structural models underpredict corporate bond credit spreads, particularly in the short end. ${ }^{1}$ Reasons for the poor performance may lie in shortcomings in the models as well as factors other than default risk in the corporate bond credit spread.

As noted in Duffie \& Lando (2001), it is typically difficult for investors in the secondary credit markets to observe a firm's assets directly, either because of noisy or delayed accounting reports or other barriers to monitoring. Instead, investors must draw inference from the available accounting data and other publicly available information. As a consequence they build a model where credit investors are not kept fully informed on the status of the firm, but receive noisy unbiased estimates of the asset value at selected times. This intuitively simple framework has a significant implication for the term structure of credit spreads.

In particular, for firms with perfectly measured assets credit spreads are relatively small at short maturities and zero at zero maturity, regardless of the riskiness of the firm. However, if firm assets periodically are observed with noise, credit spreads are strictly positive under the same limit because investors are uncertain about the distance of current assets to the default barrier.

This paper contributes to the existing literature by estimating the component of the term structure of credit spreads associated with a lack of accounting transparency. $^{2}$ To this end, credit default swap (CDS) spreads at the 1, 3, 5, 7 and 10-year maturity for a large cross-section of firms are used together with a newly developed measure of accounting transparency by Berger et al. (2006). This transparency measure is related to CDS spreads in two main ways.

First, it is used to estimate a gap between the high and low transparency credit curves. This gap interpreted as a transparency spread is estimated at 20 bps at the 1-year maturity and narrows to 14, 8, 7 and 5 bps at the 3, 5, 7 and 10-year maturity, respectively. The downward-sloping term structure of transparency spreads is

\footnotetext{
${ }^{1}$ See e.g. Jones, Mason \& Rosenfeld (1984), Ogden (1987), Huang \& Huang (2003) and Eom, Helwege \& Huang (2004).

${ }^{2}$ Consistent with the literature, we use the terms "accounting noise" and "accounting transparency" interchangeably. If the noise in the reported asset value is low, the accounting transparency is high.
} 
highly significant in the short end but most often insignificantly estimated above the 5-year maturity. Furthermore, the effect of accounting transparency is largest for the most risky firms. These results are robust across alternative econometric specifications controlling for within cluster correlations and a large set of control variables.

Second, we analyze each maturity class in isolation using the raw transparency measure and a rank transformation. In this specification, the equal maturities across firms fixed through time in the CDS data allow the control variables to enter nonlinearly across maturities classes. Since insights from above are preserved, the results are supportive of hypotheses derived from Duffie \& Lando (2001) and add an explanation to the underprediction of short-term credit spreads by traditional structural models.

However, the explanatory power of accounting transparency and a typical set of control variables is small for less risky firms. This observation is supportive of the problems in earlier studies, when explaining the credit spreads of low-yield firms using structural models. This paper suggests that variables other than accounting transparency are needed, also in the short end.

The results contrast an earlier study by $\mathrm{Yu}$ (2005), who analyzes corporate bond credit spreads in 1991 to 1996 using the AIMR analyst ranking of corporate disclosure. He attributes a u-shaped transparency spread with the largest affect at longer maturities to a discretionary disclosure hypothesis, where firms hide information that would adversely affect their long-term outlook. While Duffie \& Lando (2001) assume an exogenous unbiased accounting noise, the theory of discretionary disclosure starting with Verrecchia (1983) suggests that withheld information may signal hidden bad news about a company. Consistent with the term structure implications in Duffie \& Lando (2001), our study shows that the transparency spread is downward-sloping in the CDS market.

Although a close relation exists between corporate bond and CDS spreads (Duffie (1999)), the latter are preferable from several perspectives when analyzing the determinants of the shape of the credit curve. First, the fixed maturities in CDS contracts make term structures directly comparable across firms and time. There is no maturity shortening as there would be with corporate bonds, and we are not forced to interpolate maturities to compare spreads in the cross-section.

Second, quotes at different maturities should be compared on the same curve, and a study of multiple maturity observations for a given firm at a given date is in effect only possible in the CDS market. Third, a use of CDS spreads avoids any noise arising from a misspecified risk-free yield curve (Houweling \& Vorst (2003)). 
Fourth, as shown in Lando \& Mortensen (2005) and Agrawal \& Bohn (2005), the shape of the corporate bond credit curve depends on deviations from par under the realistic recovery of face value assumption. As Yu (2005) focuses on secondary market yields this technical effect may influence his results. The same effect is not present in the CDS market as CDS spreads are closely related to par bond spreads.

Fifth, CDS contracts are less likely to be affected by differences in contractual arrangements such as embedded options, guarantees, covenants and coupon effects. Although bonds with e.g. call features may be deliverable in default this effect is present across the entire spectrum of CDS quotes.

Sixth, several recent studies find that CDS spreads are a purer measure of credit risk and represent more timely information than corporate bonds. Nondefault components stemming from asymmetric taxation and illiquidity have been compared across corporate bond and CDS markets. ${ }^{3}$ However, the component due to imprecisely observed assets, let alone the term structure implications, is much less understood.

A reason for the lack of evidence on the impact of accounting transparency is the difficulty in constructing an empirical measure of a firm's overall information quality. The accounting literature explaining e.g. the cost of capital has relied on the AIMR analyst ranking of corporate disclosure. Analyzing the cost of debt, Sengupta (1998) finds a negative relationship between the AIMR measure and offering yields. This measure is also adopted by Yu (2005), with a resulting sample almost entirely made up of investment grade firms. As the measure ends in 1996, it cannot be related to CDS curves.

However, a newly developed measure of accounting transparency by Berger et al. (2006) can be readily calculated for a large sample of firms. This allows us to study a large set of credit curves across rating categories. The idea behind the measure is that controlling for the idiosyncratic cash flow volatility, the better a firm's information quality the higher it's firm-specific equity return volatility. Berger et al. (2006) conduct several tests to assess their measure, and find results in accordance with intuition. Our application in the credit derivatives market provides additional evidence to the validity of the measure.

\footnotetext{
${ }^{3}$ Blanco, Brennan \& Marsh (2005) find that the CDS market leads the corporate bond market. Longstaff, Mithal \& Neis (2005) find a significant non-default related component in the corporate bond credit spread correlated with illiquidity proxies. Ericsson, Reneby \& Wang (2006) find this not to be present in CDSs. Elton, Gruber, Agrawal \& Mann (2001) document a tax premium of 29 to 73 percent of the corporate bond credit spread, depending on the rating. Related studies on corporate bonds include Delianedis \& Geske (2001) and Huang \& Huang (2003).
} 
This paper is related to Sarga \& Warga (1989), Fons (1994), Helwege \& Turner (1999), Lando \& Mortensen (2005) and Agrawal \& Bohn (2005) who analyze the slope of the credit curve as a function of credit quality. Ignoring noisy asset reports, standard theory predicts an upward-sloping credit curve for high quality firms and a humped shaped or mostly downward-sloping credit curve for low quality firms. However, these papers are silent on decomposing the curve and the effect of accounting transparency.

Early studies mainly analyze the 5-year maturity, which is considered the most liquid point on the curve. This paper contributes to an increasing literature analyzing the entire term structure of CDS spreads. In addition to Lando \& Mortensen (2005) and Agrawal \& Bohn (2005) this includes Huang \& Zhou (2007), who conduct a consistent specification analysis of traditional structural models. Although the 5-year maturity dominates our data, a significant number of observations are found at the 1,3, 7 and 10-year maturity.

Finally, the paper is related to studies on the determinants of credit spreads such as Collin-Dufresne, Goldstein \& Martin (2001), Campbell \& Taksler (2003), Ericsson, Jacobs \& Oviedo (2005), Cremers, Driessen, Maenhout \& Weinbaum (2006) and Cao, Yu \& Zhong (2006). These papers analyze the explanatory power of traditional structural variables such as leverage, asset volatility and risk-free interest rates, but are silent on different maturity classes and accounting transparency. Finally, Güntay \& Hackbarth (2007) study the relation between corporate bond credit spreads and the dispersion of equity analysts' earnings forecasts.

The outline of the paper is as follows. Section 2 reviews the Duffie \& Lando (2001) model and motivate the hypotheses. This section also shows a formula for the CDS spread that avoids a double integral and is easily comparable with the case of perfect information. Section 3 outlines the accounting transparency measure developed in Berger et al. (2006), while section 4 presents the data. The descriptive statistics are presented in section 5 , while section 6 and 7 contain the empirical results and a robustness analysis. Section 8 concludes. Appendix A and B give details behind the Duffie \& Lando (2001) model and the transparency measure, respectively.

\section{Hypotheses}

In traditional structural credit risk models, default is defined as the first hitting time of a perfectly observed diffusion process on a default barrier. This default 
barrier can be exogenously determined as in e.g. Black \& Cox (1976) and Longstaff \& Schwartz (1995) or endogenously derived as in e.g. Leland (1994) and Leland $\&$ Toft (1996).

As shown in Leland (2004), these models do a reasonable job in predicting longer horizon default rates while the prediction of short-term default rates is far to low. The problem is that conditional on the firm value being above the barrier, the probability that it will cross the barrier in the next $\Delta t$ is $o(\Delta t)$ and the conditional default probability converges to zero as time goes to zero.

Duffie \& Lando (2001) argue that it is typically difficult for investors in the secondary credit markets to perfectly observe the firm's assets and introduce accounting noise into a Leland (1994)-type model. More specifically, the value of the firm's assets is assumed to follow a geometric Brownian motion unobservable to the credit investors. Instead, the firm periodically issues noisy unbiased accounting reports, which makes investors uncertain about the distance of the assets to the default barrier.

Conditional on the accounting reports and the fact that the firm has not defaulted investors are able to compute a distribution of the value of assets. This conditional distribution of assets is reproduced in Figure 1 for various degrees of accounting noise $a$ and a set of base case parameters. The crucial parameter $a$ measures the standard deviation of the normal noise-term added to the true asset value. A lower $a$ thus represents a higher degree of accounting transparency and less uncertainty about the true asset value. When $a$ approaches zero the distribution will eventually collapse around the latest reported asset value.

According to Duffie \& Lando (2001) this simple mechanism of uncertainty surrounding the true asset value is enough to produce a default probability within the next $\Delta t$ that is $O(\Delta t)$. In fact, they show that as time goes to zero the limit of the conditional default probability is the intensity of the default stopping time $\tau$. The Duffie \& Lando (2001) model is further described in appendix A.

The payments in a CDS fit nicely into a continuous-time framework since the accrued premium must also be paid if a credit event occurs between two payment dates. In appendix A we show that with continuous payments the CDS spread with maturity $T$ can be written as

$$
c(0, T)=r(1-R) \frac{\int_{\underline{v}}^{\infty} G(x, T) g(x) d x}{1-e^{-r T} \int_{\underline{v}}^{\infty}(1-\pi(T, x-\underline{v})) g(x) d x-\int_{\underline{v}}^{\infty} G(x, T) g(x) d x},
$$


where $r$ is the risk-free interest rate and $R$ is the recovery rate. ${ }^{4} \pi(T, x-\underline{v})$ denotes the probability of first passage time of a Brownian motion with constant drift and volatility parameter from an initial condition $(x-\underline{v})>0$ to a level below zero at time $T$, where $x$ and $\underline{v}$ denote the logarithm of the asset value and default barrier, respectively. The formulas for $\pi(T, x-\underline{v})$ and $G(x, T)$ are given in closed form in the appendix together with the conditional density function of the logarithm of assets $g(x)$ at the time of issuance of the CDS.

In the case of perfect information the integral and the density function $g(x)$ simply disappears, leading to a closed form solution for the CDS spread known from traditional structural credit risk models.

In Figure 2, the term structure of CDS spreads in equation (1) is shown for the associated conditional distribution of assets in Figure 1 and the various degrees of accounting noise $a$. Also depicted is the traditional case of perfect information $a=0$, where the spread approaches zero as maturity goes to zero. However, this is not the case when noisy reports are introduced. As a becomes larger, the probability that the asset value is, in fact, close to the default barrier and may cross in a short period of time increases, resulting in higher short-term spreads. The difference in spreads due to a lack of accounting transparency is less pronounced at longer maturities.

Figure 3 and 4 depict the case of a lower leverage and a lower asset volatility, respectively. This captures the effect of accounting transparency on CDS spreads for less risky firms than the base case. The spreads are compressed compared to Figure 2, indicating that we should expect a lower absolute effect of accounting transparency for less risky firms.

Finally, an adverse effect of the exogenous and unbiased accounting noise in the Duffie \& Lando (2001) model, which is also addressed in Yu (2005), is depicted in Figure 5. In this case, the current report shows a substantially lower asset value than the lagged report, which leads to the counterintuitive result that a higher transparency is associated with higher spreads for most parts of the term structure. With perfect information the lagged report is irrelevant, but as $a$ increases and transparency is reduced the current report becomes less reliable and more weight is put on the lagged report suggesting a higher asset value. ${ }^{5}$ Hence, more mass of the conditional asset distribution is shifted towards higher asset values implying

\footnotetext{
${ }^{4}$ The formula in Duffie \& Lando (2001) is based on semiannually payments and a double integral over time and the asset density. The assumption of continuous payments implies that it is only necessary to calculate a single integral numerically to evaluate the CDS spread.

${ }^{5}$ Under perfect information, the term-structure of CDS spreads in Figure 2 and 5 are identical.
} 
lower credit spreads.

This example illustrates the need for structural models to incorporate accounting transparency as an endogenous choice. With discretionary disclosure this situation would not arise since the firm would choose not to reveal the bad news in the first place. The theory of discretionary disclosure starting with Verrecchia (1983) suggests that withheld information may signal hidden bad news about a company. As a result, a lower transparency is associated with higher credit spreads.

[Figures 1,2,3,4 and 5 about here ]

The above intuition leads to the following hypotheses for the qualitative effect of accounting transparency on CDS spreads.

H1. Firms with a lower level of accounting transparency have higher CDS spreads.

H2. The effect of accounting transparency is more pronounced at shorter maturities, leading to a term structure effect.

H3. A stronger effect of accounting transparency is expected for more risky firms.

The first hypothesis is due to the theory of discretionary disclosure, while the second and third are due to Duffie \& Lando (2001). At reasonable parameter values, Duffie \& Lando (2001) do not predict a significant spread due to noisy reports above the 5 -year maturity.

The term structure effect of discretionary disclosure is less obvious and depends on the nature of information that a firm tries to conceal. A temporary shock to the firm value affects short-term spreads, while a permanent shock such as a negative outlook on earnings growth affects long-term spreads. Yu (2005) notes that the positive net-worth requirement effectively present in short-term debt implies that firms have little incentive to conceal information that they are soon forced to reveal anyway. ${ }^{6}$ Hence, he argues that discretionary disclosure is most likely to concern permanent shocks and long-term spreads.

\section{Measuring Accounting Transparency}

To assess accounting transparency, we construct a newly developed measure by Berger et al. (2006) that can be readily calculated for a large sample firms. The

\footnotetext{
${ }^{6}$ See Leland (1994) for the relationship between short-term debt and positive net-worth requirements.
} 
idea behind the measure is that when pricing equity, investors use a weighted average of reported earnings and industry earnings. Investors put more weight on the firm's reported earnings when the accounting transparency is high. It turns out that the measure of accounting transparency is the ratio of idiosyncratic equity return volatility to the idiosyncratic volatility in earnings growth. Appendix B establishes the theoretical link between the measure and accounting transparency. The current section implements it as prescribed in Berger et al. (2006).

In particular, to measure transparency empirically in year $t$ two regressions are performed. The first uses monthly data from year $t-5$ to $t-1$ to calculate the idiosyncratic volatility in equity returns

$$
r_{t}^{j}=a_{j}^{r}+b_{j}^{r, M} r_{t}^{M}+b_{j}^{r, I} r_{t}^{I}+\varepsilon_{t}^{r, j}
$$

where $r_{t}^{j}$ is firm $j^{\prime} s$ monthly equity return, $r_{t}^{M}$ is the CRSP value-weighted market return and $r_{t}^{I}$ is a value-weighted industry return using the 48 industries in Fama \& French (1997). ${ }^{7}$ To ensure the accuracy at least 50 valid monthly returns are required for each firm. The annualized idiosyncratic volatility of returns $I V O L_{t, j}^{r}$ is then calculated as $\sqrt{12} * \operatorname{std}\left(\varepsilon^{r, j}\right)$.

The second regression uses quarterly data from year $t-5$ to $t-1$ to calculate the idiosyncratic volatility in earnings growth

$$
E G_{t}^{j}=a_{j}^{E G}+b_{j}^{E G, M} E G_{t}^{M}+b_{j}^{E G, I} E G_{t}^{I}+\varepsilon_{t}^{E G, j},
$$

where $E G_{t}^{j}$ is the annual growth rate in firm $j^{\prime} s$ quarterly operating earnings calculated as $\frac{\text { operating earnings } t}{\text { operating earnings } t-4}-1 .^{8}$ The growth rate is measured between identical quarters to avoid complications that arise from seasonality. If the lagged earnings are negative the growth rate is not meaningful and that particular growth rate is dropped. ${ }^{9}$ To ensure the accuracy, we require at least 15 quarters of data. $E G_{t}^{M}$ is the earnings-weighted average market growth rate and $E G_{t}^{I}$ is the earningsweighted average growth rate in the Fama \& French (1997) industries.

The idiosyncratic volatility in earnings growth $I V O L_{t, j}^{E G}$ is $\operatorname{std}\left(\varepsilon^{E G, j}\right)$, and the measure is finally constructed as the ratio of the idiosyncratic volatility in equity

\footnotetext{
${ }^{7}$ Market capitalization is used as weights when calculating the market and industry returns. All firms in the CRSP database enter the return and later earnings growth calculations.

${ }^{8}$ The quarterly operating earnings is data item number 8 in the Compustat database.

${ }^{9}$ Since operating income and not net income is used the loss of observations is small.
} 
returns to the idiosyncratic volatility in earnings growth

$$
\delta_{t, j}=\frac{I V O L_{t, j}^{r}}{I V O L_{t, j}^{E G}}
$$

Hence, the idiosyncratic volatility in equity returns is driven by the idiosyncratic volatility in earnings growth and the firm's information quality. The measure is theoretically constrained to the unit interval, and a higher score corresponds to a higher accounting transparency.

Berger et al. (2006) calculate the measure for 41,615 firm-years in 1980 to 2004 and find empirical evidence in accordance with intuition and theory. In particular, they assess the validity of the measure by relating it to different measures of disclosure quality and the cost of equity. First, the measure increased after two new regulations that increased mandatory disclosures in the pension and oil and gas sectors. Second, the measure is strongly correlated with the investor relations component of the AIMR measure and weakly correlated with the total AIMR measure. Third, firms with a higher measure are followed by more analysts and have a lower forecast dispersion of earnings per share. Finally, the measure is negatively related to three estimates of the cost of equity.

In the end, we necessarily test the joint hypotheses of the validity of the accounting transparency measure developed in Berger et al. (2006), and the term structure effects suggested in Duffie \& Lando (2001). Our application in the credit derivatives market provides additional evidence to the validity of the measure.

\section{Data}

Data on CDS spreads is provided by the ValuSpread database from Lombard Risk Systems, dating back to July 1999. The number of entities and frequency of quotes increase significantly through time, reflecting the growth and improved liquidity in the market. This data is also used by Lando \& Mortensen (2005) and Berndt, Jarrow \& Kang (2006). The data consists of mid-market CDS quotes on both sovereigns and corporates with varying maturity, restructuring clause, seniority and currency. For a given date, reference entity and contract specification, the database reports a composite CDS quote together with an intra-daily standard deviation of the collected quotes. The composite quote is calculated as a midmarket quote by obtaining quotes from up to 25 leading market makers. This offers a more reliable measure of the market spread than using a single source, and 
the standard deviation measures how representative the mid-market quote is for the overall market.

To test the effect of accounting transparency on the term structure of CDS spreads, contracts with a maturity of $1,3,5,7$ and 10 years are analyzed. We furthermore confine ourselves to composite CDS quotes on senior unsecured debt for North American corporate obligors with currencies denominated in US dollars. Regarding the specification of the credit event, we follow large parts of the literature in using contracts with a modified restructuring clause.

To generate a proper subsample, several filters are applied to the data. First, the CDS data is merged with quarterly balance sheet data from Compustat and daily stock market data from CRSP. The quarterly balance sheet data is lagged one month from the end of the quarter to avoid the look-ahead bias in using data not yet available in the market. Second, firms from the financial and utility sector are excluded.

Third, the composite quote at a given maturity must have a certain quality. Therefore, we define the relative quote dispersion as the intra-daily standard deviation of collected quotes divided by the mid-market quote. We follow Lando \& Mortensen (2005) and delete all daily mid-market quotes with an intra-daily quote dispersion of zero or above 20 percent. Fourth, 1, 3, 5, 7 and 10-year constant maturity treasury yields are obtained from the Federal Reserve Bank of St. Louis.

Fifth, we restrict the sample to end-of-month dates. This selection criteria is also applied by Lando \& Mortensen (2005), as these dates have the highest number of quotes. This leaves us with 31,525 month-end consensus quotes distributed across 8,309 curves and 432 firms. Finally, the dataset is merged with the annual transparency measure calculated for each firm in section 3. The result is 25,599 month-end quotes distributed across 6,756 curves, 368 firms and 890 firm-years from May 2002 to September 2004, with sufficient data to calculate the transparency measure developed in Berger et al. (2006). ${ }^{10}$

\section{Descriptive Statistics}

Table 1 illustrates the distribution of the annual accounting transparency measure. Panel A represents statistics based on the pooled measure across firms and years,

\footnotetext{
${ }^{10}$ One firm is excluded, Colgate Palmolive, as the transparency measure is calculated at 10.23 , 11.56 and 11.89 in year 2002-2004. This persistently large score far above the remaining firms might indicate a data problem specific to the firm.
} 
while statistics in Panel B are calculated after averaging the measure for each firm in the time-series. The pooled mean and median are 0.50 and 0.29 , respectively. A few high transparency scores drive up the average, and about 10 percent of the sample firm-years have scores larger than the theoretical upper bound of 1 . A similar result based on a larger set of firms is found in Berger et al. (2006), who attribute it to possible time-varying expected returns.

The standard deviation is 0.61 and the inter-quartile range is 0.44 . The same variation is observed in panel $\mathrm{B}$ after averaging the measure in the time-series, indicating a large variation in accounting transparency across the firms. The data allow for a maximum of 3 consecutive annual transparency scores with associated CDS data for each firm. An untabulated mean and median annual absolute change of 0.17 and 0.04 , respectively, indicate a somewhat persistent transparency measure in the time-series.

[Table 1 about here ]

Table 2 presents summary statistics of key variables across the senior unsecured credit rating from Standard \& Poor's. The variables presented are averages across time and across firms. Consistent with the predictions of structural credit risk models, a lower rating is associated with a higher credit spread level represented by the 5-year CDS spread, a higher equity volatility and a higher leverage. The equity volatility is calculated using 250 days of equity returns, and leverage is total liabilities divided by the sum of total liabilities and equity market capitalization.

[Table 2 about here ]

A better credit rating is associated with a higher accounting transparency. This observation and a correlation of 0.16 in Table 3 provide additional evidence to the validity of the transparency measure as documented empirically in Berger et al. (2006). As noted in Sengupta (1998) and Yu (2005), credit agencies claim to have incorporated the quality of information disclosure in the credit ratings. Hence, we follow Sengupta (1998) and Yu (2005) and use credit ratings with caution when controlling for the cross-sectional determinants of credit spreads other than accounting transparency. We use an alternative set of control variables from studies on the determinants of credit spreads such as equity volatility, leverage, liquidity and the risk-free yield curve. However, we also analyze whether credit ratings absorb the effect of accounting transparency on the term structure of CDS spreads.

As a final remark, the correlation between the accounting transparency measure 
and leverage and volatility, respectively, is estimated at -0.16 and -0.08 . This is of similar sign and magnitude as the correlations found in $\mathrm{Yu}$ (2005) based on the AIMR measure in 1991 to 1996.

[Table 3 about here ]

The distribution of the CDS spreads across credit ratings and maturities is illustrated in Table 4 Panel A. The mean consensus quote across time and firms is found in the first row, while the number of observations and the mean relative quote dispersion are found in the second and third row, respectively. Panel B contains the statistics for full month-end curves with observations at all maturities at monthend for a given firm. By considering full curves, the mean consensus quotes within a given rating class are comparable across maturities, since all averages are calculated from the same set of dates and firms. As expected, the mean consensus quotes increase monotonically with maturity for high credit quality firms and decrease monotonically with maturity for the lowest credit quality firms. ${ }^{11}$

The 5-year maturity accounts for the highest number of observations, but even the least observed 1-year maturity accounts for almost 15 percent of the observations. Across ratings the lower end of the investment grade segment has the highest number of observations. However, we are able to study a significant proportion of sample spreads across maturities in the low credit quality segment. For BB-rated firms the sample consists of 449 to 757 month-end quotes for each maturity and 342 full curves, while the number of quotes for B-rated firms ranges from 66 to 87 with 50 full curves. ${ }^{12}$

Lando \& Mortensen (2005) interpret the relative quote dispersion as a proxy for liquidity. The more agreement about a quote, the higher the liquidity for that particular credit. Adopting this liquidity proxy, we see a liquidity smile for a fixed rating across maturities. This is consistent with the fact that the 5-year maturity is considered the most liquid point on the curve. However, the difference in the mean relative quote dispersion across maturities is small.

[Table 4 about here ]

\footnotetext{
${ }^{11}$ Theory predicts an upward-sloping credit curve for high quality firms and a humped shaped or mostly downward-sloping credit curve for low quality firms. While the first is well-established in the empirical literature, the latter is more controversial. See Sarga \& Warga (1989), Fons (1994), Helwege \& Turner (1999), Lando \& Mortensen (2005) and Agrawal \& Bohn (2005).

${ }^{12}$ For comparison, $\mathrm{Yu}$ (2005) studies 0 speculative grade bonds in 1991-1994, 4 in 1995 and 15 in 1996 .
} 
In the end, the measure developed in Berger et al. (2006) allows us to relate accounting transparency to CDS curves for a large cross-section of firms. Importantly, the distribution of CDS spread observations across credit quality and maturity is desirable in our attempt to understand the impact of accounting transparency on the term structure of CDS spreads. The accounting transparency varies considerably in the large cross-section but less in our relatively short time-series. Furthermore, some evidence indicates that credit spread changes in the time-series are mostly driven by market factors that tend to overwhelm the effect of firm-level characteristics. ${ }^{13}$ Hence, cross-sectional regressions form our benchmark approach. This makes the results comparable to Yu (2005), as cross-sectional regressions constitute the only regression framework in his study. Later, various econometric specifications are introduced to ensure that the results are not driven by spurious correlations.

\section{Empirical Results}

First, we estimate a gap between the high and low transparency credit curves. This allows us to directly estimate the term structure of transparency spreads. We then study a restricted set of full curves and estimate the transparency spread term structure for high and low risk firms.

\subsection{The Term Structure of Transparency Spreads}

Duffie \& Lando (2001) predict accounting transparency to be an important variable in explaining credit spreads in the short end. At reasonable parameter values, the model does not predict a significant impact of accounting transparency above the 5-year maturity. However, discretionary disclosure may still imply an effect in the long end.

The corporate bond data used in $\mathrm{Yu}$ (2005) consists of bonds with unequal and shortening maturities and durations. This forces him to construct a piecewise linear function of bond maturity across the firms at each month-end. He then estimates the level of the credit spread at the constructed and artificial knot points. As a starting point, we adopt a comparable specification and estimate the gap

\footnotetext{
${ }^{13}$ The results in Collin-Dufresne et al. (2001) suggest that the time-series variation in corporate bond credit spreads is mainly determined by local supply and demand shocks independent of credit risk factors and liquidity proxies. Huang \& Zhou (2007) find that five popular structural models cannot capture the time-series behavior of CDS spreads.
} 
between the high and low transparency credit curves. However, we estimate the gap between the two curves at the equal, fixed and therefore directly comparable maturities in the CDS data, and interpret the gap as a transparency spread term structure.

In particular, define $d$ as a dummy variable that equals 1 if a firm's transparency measure calculated in equation (4) in a given year ranks above the median score. Furthermore, define $m_{T}$ as a variable that attains a value of 1 if the CDS spread has a maturity of $T=1,3$ if the CDS spread has a maturity of $T=3$ and so forth. Hence, in the linear combination $\beta_{1} m_{1}+\beta_{2} m_{3}+\beta_{3} m_{5}+\beta_{4} m_{7}+\beta_{5} m_{10}$ the coefficient $\beta_{i}$ represents the level of the term structure at maturities $1,3,5,7$ and 10 years. Now, define $d m_{T}$ as the product of the transparency dummy $d$ and $m_{T}$. The regression coefficient in front of this term can be directly interpreted as the transparency spread, i.e. the gap between the high and low transparency credit curves at the given maturity.

Hence, we run monthly cross-sectional regressions of CDS spreads on the transparency variables, volatility, leverage and relative quote dispersion ${ }^{14}$

$$
\begin{aligned}
\text { Spread }_{i t}= & \beta_{1 t} m_{1 i t}+\beta_{2 t} m_{3 i t}+\beta_{3 t} m_{5 i t}+\beta_{4 t} m_{7 i t}+\beta_{5 t} m_{10 i t} \\
& +\beta_{6 t} d m_{1 i t}+\beta_{7 t} d m_{3 i t}+\beta_{8 t} d m_{5 i t}+\beta_{9 t} d m_{7 i t}+\beta_{10 t} d m_{10 i t} \\
& +\beta_{11 t} V o l_{i t}+\beta_{12 t} L e v_{i t}+\beta_{13 t} Q d i s p_{i t}+\varepsilon_{i t} .
\end{aligned}
$$

The coefficient estimates are averaged in the time-series and standard errors are calculated following Fama \& MacBeth (1973). Table 5 displays the results. Focusing on the first column, the transparency spread is highly significant and estimated at 23 bps at the 1-year maturity and 20, 13, 13 and 11 bps at the remaining maturities. Particularly the transparency spread in the short end represents a considerable part of the average CDS spread level of 130 to 140 bps across maturities as reported in Table 4.

As expected, the volatility and leverage are highly significant in explaining credit spreads. However, the relative quote dispersion varies in significance and has a negative coefficient estimate. If proxying for liquidity, the coefficient is expected to be positive. Hence, although the variable allows for reasonable interpretations on average as liquidity in Table 4, it is questionable whether the relative quote dispersion captures differences in liquidity as suggested in Lando \& Mortensen (2005). As the control variable only has a minor impact on the remaining coefficient

\footnotetext{
${ }^{14}$ To facilitate interpretation the regression equation does not include an intercept term. Hence, the $R^{2}$ is not reported under this empirical specification.
} 
estimates and significance, we keep it in our future regressions. ${ }^{15}$

Firms usually have corporate bonds outstanding with just a few (or one) maturities. Hence, studying multiple maturity observations for a given firm at a given date is in effect only possible in the CDS market, and therefore not pursued in $\mathrm{Yu}$ (2005). Table 5 also contains the regression results for a restricted set of full month-end curves with observations at all maturities at month-end for a given firm. This makes CDS spreads directly comparable across maturities as all observations are from the same set of dates and firms. As noted in Helwege \& Turner (1999) and Lando \& Mortensen (2005), firms with heterogenous credit quality are known to populate different ends of the corporate bond credit curve. This maturity bias is avoided when studying full curves in the CDS market.

A highly significant downward-sloping term structure of transparency spreads also emerges from a study of full curves. From a transparency spread of $24 \mathrm{bps}$ at the 1-year maturity it decreases to 13 bps at the longest maturity.

\section{[Table 5 about here ]}

The results in Table 5 to some extend support the findings in Yu (2005). While agreeing on the statistically and economically significant transparency spread in the short end, $\mathrm{Yu}$ (2005) finds a widening transparency spread at longer maturities. In fact, he finds the transparency spread larger in the long end than short end. He attributes this observation to the discretionary disclosure hypothesis where firms hide information that would adversely affect their long-term outlook. ${ }^{16}$ In alternative econometric specifications building on the interpretation of $d m_{T}$ as a transparency spread, we later show that the term structure of transparency spreads is not only strictly downward-sloping but most often insignificant in the long end.

As argued in section 2, a stronger effect of accounting transparency is expected for more risky firms. Therefore, each month the firms are separated into high and low leverage and volatility groups by the respective medians. The regression in (5) is then presented for each group in Table $6 .{ }^{17}$

\footnotetext{
${ }^{15}$ Unreported results show that the presence or omission of relative quote dispersion has no impact on any results reported in the paper.

${ }^{16}$ Although Yu (2005) has only few observations in the longest end, he calculates a transparency spread at the 30-year knot point coinciding with the maximum corporate bond maturity. Hence, this estimate is likely to be less reliable. However, while our transparency spread term-structure remains downward-sloping, his exhibits a $u$-shape already at the 10-year knot point. More precisely, he estimates a transparency spread of 11,3,9 and 13 bps at the 0, 5, 10 and 30-year knot points.

${ }^{17}$ As noted in Table 3, the correlation between the transparency measure and leverage and
} 
For the low leverage and low volatility groups, the effect of accounting transparency on credit spreads is small and of varying significance. While the transparency spread term structure is insignificantly estimated for low leverage firms, it is most often significant for the low volatility firms. However, the transparency spread is estimated at around 3 to $7 \mathrm{bps}$, which constitutes a small part of the average CDS spread level for low volatility firms of 69 to 84 bps across maturities.

In contrast, the effect of accounting transparency is large for the high leverage and high volatility groups. For the high leverage group the term structure of transparency spreads is highly significant and estimated at 29, 34, 23, 22 and 14 bps across maturities. For the high volatility group it is estimated at 33, 26, 14, 12 and 7 bps. The transparency spread is highly significant in the short end while insignificantly estimated at longer maturities.

Finally, for firms with both a high leverage and a high volatility, the term structure of transparency spreads is very steep and estimated at 51, 40, 23, 22 and 15 bps. Again, the transparency spread is highly significant in the short end while weakly significant at the longest maturity. Compared to an average spread of 180 to 220 bps across maturities in both groups, the transparency spread constitutes a relatively larger component of the CDS spread level for risky firms. Unreported results on full curves support these insights.

\section{[Table 6 about here ]}

To summarize at this point, we find a highly significant downward-sloping term structure of transparency spreads. Furthermore, the effect of accounting transparency on the term structure of CDS spreads is largest for the most risky firms. We now show that the term structure of transparency spreads remains downwardsloping under alternative econometric specifications. Furthermore, while highly significant in the short end, it is often insignificant at maturities exceeding 5 years. These findings are in line with the hypotheses derived from Duffie \& Lando (2001).

volatility, respectively, is -0.16 and -0.08 . As an extreme example, all firms with below median leverage or volatility could have above median accounting transparency. In such a case, the regression would not be able to identify a relation between transparency and CDS spreads. However, the summary statistics on accounting transparency for each high and low leverage or volatility group are not far from those reported in Table 1. 


\section{Robustness Analysis}

This section conducts various robustness tests, e.g. controlling for a residual dependence across a given credit curve. Finally, the equal maturities across firms fixed through time in the CDS data allow the control variables to impact CDS spreads nonlinearly across maturities in a final specification. This exercise can be based on the raw transparency measure and a rank transformation.

\subsection{Alternative Econometric Specifications}

Table 7 presents the results of estimating the gap between the high and low transparency credit curves under different econometric specifications. The benchmark regression (1) is a pooled OLS regression with White standard errors. As standard errors in the remaining regressions are robust to heteroscedasticity, differences in standard errors across columns (1) to (8) are due to within cluster correlations including the Fama \& MacBeth (1973) standard errors in (7) and (8). ${ }^{18}$

Clustered standard errors (also called Rogers standard errors) account for a residual dependence created by a firm effect, time effect or similar. The correlation can be of any form as no parametric structure is assumed. Regression (2) controls for a possible correlation in residuals across maturities for a given firm and month, by allowing for within cluster correlation at the curve level. The clustered standard errors in regression (3) control for a possible time effect, where the residuals of a given month may be correlated across different firms and maturities.

Regression (4) to (6) extend these specifications and control for a constant time effect. We do that by addressing the latter parametrically using monthly dummies. Clustering by month while including monthly dummies allows one to separate the time effect into a constant and non-constant part. A non-constant time effect is present, if a shock in a given month has a different effect on different firms.

The cross-sectional Fama \& MacBeth (1973) regression from Table 5 is repeated in regression (7). This regression also accounts for a cross-correlation in residuals stemming from a time effect, and it assumes that the monthly coefficient estimates are independent of each other. However, when estimating the standard error of their mean the annual accounting transparency measure may imply a serial correlation in the monthly coefficient estimates. We adopt the method in Abarbanell \& Bernard (2000) and present the adjusted standard errors in regression (8). This adjustment is designed to correct for a firm effect arising from persistent

\footnotetext{
${ }^{18}$ See the survey of panel data methods used in finance by Petersen (2007).
} 
firm characteristics. ${ }^{1920}$

The conclusion from Table 7 Panel $\mathrm{A}$ is that the transparency spread is very robust in the short end and estimated around 20 bps at the 1-year maturity. At longer maturities the transparency spread narrows and is estimated around 14, 8, 7 and 5 bps at the 3, 5, 7 and 10-year maturity, respectively. While highly significant in the short end across all specifications, the transparency spread is most often insignificantly estimated after the 7 -year maturity. The same conclusion results from Panel B, where the different econometric specifications are applied on full curves. ${ }^{21}$

[Table 7 about here ]

Table 8 repeats the specifications in Table 7 , but includes the senior unsecured credit rating from Standard \& Poor's as an additional control variable in equation (5). As noted in Sengupta (1998) and Yu (2005), credit agencies claim to have incorporated the quality of information disclosure in the credit ratings. The results show that credit ratings do not absorb the effect of accounting transparency on the term structure of credit spreads. After accounting for the information content in credit ratings, the transparency spread continues to be highly significant at the 1-year maturity and downward-sloping. However, now the gap between the high and low transparency credit curves is insignificant after the 5-year maturity. As expected, the credit rating is highly significant and a one notch increase in rating lowers the CDS spread by approximately 50 bps. Unreported results based on full curves support these findings.

[Table 8 about here ]

Consistent with empirical findings in Duffee (1998), structural models such as Longstaff \& Schwartz (1995) predict an inverse relationship between the risk-free

\footnotetext{
${ }^{19}$ To be conservative, the adjustment is not applied when the estimated serial correlation is less than zero.

${ }^{20}$ We do not report standard errors after clustering at the firm level or introducing firm dummies for a number of reasons. First, the short time-series implies that we only have 1 year of data for a significant number of firms (as noted in Table 1 the data consists of 368 firms and 890 firm-years in 2002 to 2004). This makes an identification of a firm effect separate from accounting transparency impossible. Second, as shown in Petersen (2007) the bias from a firm effect is increasing in the number of periods. Third, the inclusion of firm fixed effects would force an identification of the transparency spread from time-series changes in accounting transparency, which is unreasonable.

${ }^{21}$ Other unreported specifications such as purely cross-sectional regressions and annual crosssectional regressions based on the time-series average CDS spreads and control variables support these findings.
} 
rate and credit spreads. An increase in the risk-free rate increases the risk-neutral drift of the asset value process and reduces the risk-neutral default probability. If an increase in the slope of the risk-free yield curve increases the expected future short rate, then by the same argument as above it implies a decrease in credit spreads. From a different perspective, as noted in Collin-Dufresne et al. (2001), a decrease in the slope of the risk-free yield curve may imply a weakening economy with decreasing expected recovery rates and higher default rates. Once again, a negative relationship between the slope of the risk-free yield curve and credit spreads is expected.

The risk-free term structure variables are constant across all firms in a given month. Hence, they cannot be included in the empirical specifications from Table 7 based on Fama \& MacBeth (1973) or when including monthly dummies. Table 9 presents the results from including the slope of the yield curve in addition to credit ratings in equation (5). The slope is defined as the difference between the 10 and 1-year constant maturity treasury yields. ${ }^{22}$ The slope of the risk-free yield curve is highly significant and estimated with a negative coefficient. However, the transparency spread continues to be highly significant in the short end, downwardsloping and insignificant after the 5-year maturity.

[Table 9 about here ]

\subsection{Individual Maturity Classes}

When included in equation (5), the control variables are only allowed to induce a parallel shift in the term structure of CDS spreads. As a final exercise, we allow the control variables to impact CDS spreads nonlinearly across maturities. For that purpose, we analyze each maturity class in isolation using the raw transparency measure calculated in equation (4) and a rank transformation. This is possible since the data consists of CDS spreads with equal and fixed maturities.

For each maturity class, Table 10 Panel A presents the results of monthly cross-sectional regressions of CDS spreads on the transparency measure, volatility, leverage and relative quote dispersion

$$
\text { Spread }_{i t}=\beta_{0 t}+\beta_{1 t} \text { Transp }_{i t}+\beta_{2 t} \text { Vol }_{i t}+\beta_{3 t} \text { Lev }_{i t}+\beta_{4 t} \text { Qdisp }_{i t}+\varepsilon_{i t} .
$$

\footnotetext{
${ }^{22}$ The level of the risk-free yield curve is discussed in section 7.2 , where individual maturity classes are studied.
} 
The coefficient estimates are averaged in the time-series and standard errors are calculated following Fama \& MacBeth (1973). The average adjusted $R^{2}$ ranges from 0.58 to 0.60 and accounting transparency is significant or highly significant at all maturities. From a coefficient of -13.45 at the 1-year maturity, the coefficient on accounting transparency decreases to -6.75 and -6.68 at the 3 and 5-year maturity, respectively. After this point a u-shape kicks in with coefficients of -8.49 and -9.56 at the 7 and 10-year maturity, respectively. The variation in accounting transparency in each maturity class is similar to the variation reported in Table 1 for the entire sample. Hence, a one standard deviation increase in transparency reduces the spread by approximately 8, 4, 4, 5 and 6 bps across the curve.

Table 10 Panel B contains the regression results for the restricted set of full curves with observations at all maturities at month-end for a given firm. The resulting coefficients on accounting transparency are all highly significant and larger at $-22.28,-21.32,-19.75,-12.15$ and -17.90 at maturities of $1,3,5,7$ and 10 years, respectively. A one standard deviation increase in transparency reduces the spread by approximately 14, 13, 12, 7 and 11 bps across the curve, and main insights from the unrestricted curves in Panel A are preserved. Under alternative econometric specifications and a broader set of control variables, the impact of accounting transparency is later shown to strictly decrease with maturity.

[Table 10 about here ]

A concern is that the accounting transparency measure is a noisy estimate of "true" accounting transparency, where an interpretation of the distance between two scores in a cardinal manner is unreasonable. Hence, we transform the annual accounting transparency measure to evenly spaced observations on the unit interval $[0,1]$, and only interpret the annual ranking ordinally. A transformed score of 1(0) in a given year is assigned to the firm with highest(lowest) transparency.

Table 11 Panel A presents highly significant coefficient estimates of -36.69, $27.73,-20.11,-26.93$ and -26.89 across the curve. If a firm is able to improve it's accounting transparency from the lowest to a median ranking, say, the result is a reduction in CDS spreads of 18,14, 10, 13 and 13 bps at maturities of 1, 3, 5, 7 and 10 years, respectively. A similar conclusion is reached from full curves in Panel B.

[Table 11 about here ]

Table 12 analyzes the impact of accounting transparency for high and low risk 
firms using the annual transparency ranks. Consistent with the results in the previous section, the effect of accounting transparency is small and most often insignificant when based on firms with a low leverage and a low volatility in Panel B. However, for the most risky firms with a high leverage and a high volatility in Panel A, the coefficient estimates are -99.02, -83.78, -68.09, -70.84 and -66.29 and highly significant. Hence, if a risky firm is able to improve it's accounting transparency from the lowest to a median ranking, say, the result is a reduction in CDS spreads of 50,42, 34, 35 and 33 bps at maturities of 1, 3, 5, 7 and 10 years, respectively.

Note the large $R^{2}$ of 0.59 to 0.63 for the risky firms and the much smaller $R^{2}$ of 0.14 to 0.20 for the firms with low leverage and low volatility. This observation is supportive of the problems in earlier studies when explaining the credit spreads of low-yield firms using structural models. This paper suggests that variables other than accounting transparency are needed - also in the short end.

[Table 12 about here ]

Finally, we allow the broader set of control variables to enter nonlinearly across the curve under the alternative econometric specifications introduced earlier. ${ }^{23}$ The conclusion is a downward-sloping impact of accounting transparency across maturities that is highly robust in the short end. Across all specifications, a move from the lowest to a median transparency ranking, say, reduces the 1-year spread by approximately 15 bps.

In particular, Table 13 presents the results from including the credit rating as a control variable. In the cross-sectional regressions in Panel A and B, the coefficients on accounting transparency are insignificant or only weakly significant after the 5-year maturity. The remaining specifications in Panel C to F support a highly significant effect of accounting transparency at the 1-year maturity and a declining coefficient with varying significance at longer maturities. The credit rating is highly significant in all specifications, and $R^{2}$ increases to 0.68 compared to an $R^{2}$ around 0.60 without credit ratings in the Fama \& MacBeth (1973) regressions in Table 10 .

[Table 13 about here ]

Table 14 presents the results from including the slope of the yield curve in

\footnotetext{
${ }^{23}$ As each maturity class is analyzed in isolation, the various econometric specifications do not include standard errors robust to within cluster correlation at the curve level.
} 
addition to credit ratings. ${ }^{24}$ As before, this variable can only be included in a subset of the empirical specifications. While estimated with a highly significant negative coefficient, the slope of the yield curve only increases $R^{2}$ marginally. Accounting transparency continues to be highly significant in the short end, and the impact continues to decline as maturity increases.

[Table 14 about here ]

\section{Conclusion}

Motivated by the theoretical contribution in Duffie \& Lando (2001), this paper relates a newly developed empirical measure of accounting transparency by Berger et al. (2006) to the term structure of CDS spreads for a large cross-section of firms.

We find a highly significant effect of accounting transparency at the 1-year maturity, and a declining impact at longer maturities. Estimating the gap between the high and low transparency credit curves, the transparency spread is estimated around 20 bps at the 1-year maturity. At longer maturities, the transparency spread narrows and is estimated at 14, 8, 7 and 5 bps at the 3, 5, 7 and 10year maturity, respectively. While highly significant in the short end and robust across alternative econometric specifications and control variables, the impact of accounting transparency is not robust and most often insignificantly estimated for maturities exceeding 5 years. Finally, the effect of accounting transparency on the term structure of CDS spreads is largest for the most risky firms.

These results are strongly supportive of the hypotheses derived from Duffie \& Lando (2001), and add an explanation to the underprediction of short-term credit spreads by traditional structural credit risk models.

The results contrast an earlier study by $\mathrm{Yu}$ (2005), who analyzes corporate bond credit spreads using the AIMR analyst ranking of corporate disclosure in 1991 to 1996 . He attributes a strongly u-shaped transparency spread with the largest effect at longer maturities to the theory of discretionary disclosure, where firms hide information that would adversely affect their long-term outlook.

Liquid CDS contracts are highly desirable when studying the determinants of the shape of the credit curve. As opposed to corporate bonds, this allows us to study multiple maturity observations for a given firm at a given day, and maturities

\footnotetext{
${ }^{24}$ Including the maturity-matched constant maturity treasury yield in addition to the slope implies that both are estimated insignificantly. However, coefficients and significance of the transparency gap are unchanged.
} 
are equal across firms and fixed through time. Furthermore, technical effects are known to impact the slope of the credit curve for corporate bonds trading off par. Hence, findings based on CDS spreads are likely to be more reliable than studies based on corporate bonds. Our study shows that the term structure of transparency spreads is downward-sloping in the CDS market across alternative econometric specifications. 


\section{A Duffie \& Lando (2001)}

The setup and results on optimal capital structure and default are close to Leland (1994) and Leland \& Toft (1996). The firm's assets $V$ are modeled as a geometric Brownian motion, which is defined on a fixed probability space $(\Omega, \mathcal{F}, Q)$. More specifically, $V(t)=\exp (Z(t))$ where

$$
Z_{t}=Z_{0}+m t+\sigma W_{t}
$$

for a standard Brownian motion $W$, a volatility parameter $\sigma$ and a parameter $m$ that determines the expected asset growth rate

$$
\mu=\frac{\log \left[E\left(V_{t} / V_{0}\right)\right]}{t}=m+\sigma^{2} / 2
$$

The firm generates cash flow at the rate $\delta V_{t}$ at time $t$ and issues debt to take advantage of the tax shields offered for interest expense at the tax rate $\theta$. The debt is modeled as a consol bond with a constant coupon rate $C$. Hence, the tax benefits are $\theta C$ until default, where $\alpha \in[0,1]$ of the asset value is lost as a frictional cost. All agents in the model are risk-neutral and discount cash flows at a constant market interest rate $r$.

The firm is operated by it's equity owners, who are completely informed at all times on the value of the assets $V$ and choose when to liquidate the firm. ${ }^{25}$ The default time is chosen endogenously by the equity owners to maximize the value of equity, and is given as the first time $\tau\left(V_{B}\right)=\inf \left\{t: V_{t} \leq V_{B}\right\}$ the asset value falls to the default barrier

$$
V_{B}(C)=\frac{(1-\theta) C \gamma(r-\mu)}{r(1+\gamma) \delta}
$$

where

$$
\gamma=\frac{m+\sqrt{m^{2}+2 r \sigma^{2}}}{\sigma^{2}}
$$

The resulting equity value is

$$
S(V, C)=\frac{\delta V}{r-\mu}-\frac{V_{B}(C) \delta}{r-\mu}\left(\frac{V}{V_{B}(C)}\right)^{-\gamma}+(\theta-1) \frac{C}{r}\left[1-\left(\frac{V}{V_{B}(C)}\right)^{-\gamma}\right],
$$

\footnotetext{
${ }^{25}$ This means that the equity owners have the information filtration $\left(\mathcal{F}_{t}\right)$ generated by $V$, where $\mathcal{F}_{t}$ is the $\sigma$-algebra generated by $\left\{V_{s}: 0 \leq s \leq t\right\}$.
} 
while the value of the consol bond is

$$
d(V, C)=\frac{(1-\alpha) V_{B}(C) \delta}{r-\mu}\left(\frac{V}{V_{B}(C)}\right)^{-\gamma}+\frac{C}{r}\left[1-\left(\frac{V}{V_{B}(C)}\right)^{-\gamma}\right]
$$

Finally, the optimal coupon is chosen such that the initial total value of the firm $S(V, C)+d(V, C)$ is maximized.

After issuance, bond and CDS investors are not kept fully informed on the status of the firm. They do understand that equity owners will force liquidation when the asset value falls to $V_{B}$, but they cannot observe the asset process $V$ directly. Instead, they receive an accounting report at selected times $t_{1}, t_{2} \ldots, t_{i}<t$ in terms of a noisy estimate of the asset value given by $\widehat{V}_{t}$, where $\log \widehat{V}_{t}$ and $\log V_{t}$ are joint normal. Specifically,

$$
Y(t)=\log \widehat{V}_{t}=Z(t)+U(t)
$$

where $U(t)$ is independent of $Z(t)$ and normally distributed with mean $\bar{u}=-\frac{a^{2}}{2}=$ $E\left(U_{t}\right)$ and variance $a^{2}=\operatorname{Var}\left(U_{t}\right)$. Hence, the standard deviation $a$ of $U_{t}$ measures the degree of accounting noise. Also observed at each $t$ is whether the firm has defaulted or not. For simplicity, it is assumed that equity is not traded in the public market and equity owners are precluded from trading in the credit market. ${ }^{26}$

Based on the information available, it is possible for the investors to calculate the conditional distribution of assets $V_{t}$. With the simple case of having observed only a single noisy asset report at time $t=t_{1}$, the density $g\left(\cdot \mid Y_{t}, z_{0}, t\right)$ of $Z_{t}$ can be computed conditional on the noisy observation $Y_{t}$, a lagged noise-free report $z_{0}$ and $\tau>t$. With $\widetilde{y}=y-\underline{v}-\bar{u}, \widetilde{x}=x-\underline{v}$ and $\widetilde{z}=z_{0}-\underline{v}$, where $\log \left(V_{B}\right)=\underline{v}$, the density is shown to be

$$
g\left(x \mid y, z_{0}, t\right)=\frac{\sqrt{\frac{\beta_{0}}{\pi}} \exp \left(-J\left(\widetilde{y}, \widetilde{x}, \widetilde{z}_{0}\right)\right)\left[1-\exp \left(\frac{-2 \widetilde{x} \widetilde{z}_{0}}{\sigma^{2} t}\right)\right]}{\exp \left(\frac{\beta_{1}^{2}}{4 \beta_{0}}-\beta_{3}\right) \Phi\left(\frac{\beta_{1}}{\sqrt{2 \beta_{0}}}\right)-\exp \left(\frac{\beta_{2}^{2}}{4 \beta_{0}}-\beta_{3}\right) \Phi\left(-\frac{\beta_{2}}{\sqrt{2 \beta_{0}}}\right)},
$$

where

$$
\begin{gathered}
J\left(\widetilde{y}, \widetilde{x}, \widetilde{z}_{0}\right)=\frac{(\widetilde{y}-\widetilde{x})^{2}}{2 a^{2}}+\frac{\left(\widetilde{z}_{0}+m t-\widetilde{x}\right)^{2}}{2 \sigma^{2} t}, \\
\beta_{0}=\frac{a^{2}+\sigma^{2} t}{2 a^{2} \sigma^{2} t}
\end{gathered}
$$

\footnotetext{
${ }^{26}$ Hence, the information filtration in the credit market is defined as $\mathcal{H}_{t}=$ $\sigma\left(\left\{Y\left(t_{1}\right), \ldots, Y\left(t_{n}\right), 1_{\left\{\tau\left(V_{B}\right) \leq s\right\}}: 0 \leq s \leq t\right\}\right)$ for the largest $n$ such that $t_{n} \leq t$.
} 


$$
\begin{gathered}
\beta_{1}=\frac{\widetilde{y}}{a^{2}}+\frac{\widetilde{z}_{0}+m t}{\sigma^{2} t}, \\
\beta_{2}=-\beta_{1}+2 \frac{\widetilde{z}_{0}}{\sigma^{2} t}, \\
\beta_{3}=\frac{1}{2}\left(\frac{\widetilde{y}}{a^{2}}+\frac{\left(\widetilde{z}_{0}+m t\right)^{2}}{\sigma^{2} t}\right)
\end{gathered}
$$

and $\Phi$ is the standard normal distribution function. Conditional on survival up to time $t$, this density gives us the conditional distribution of assets as $g(V) / V$, depicted in Figure 1. The conditional survival probability $q(t, s)=Q\left(\tau>s \mid \mathcal{H}_{t}\right)$ to some future time $s>t$ is

$$
q(t, s)=\int_{\underline{v}}^{\infty}(1-\pi(s-t, x-\underline{v})) g\left(x \mid Y_{t}, z_{0}, t\right) d x .
$$

$\pi(s-t, x-\underline{v})$ at time $t$ denotes the probability of the first passage of a Brownian motion with drift $m$ and volatility parameter $\sigma$ from an initial condition $(x-\underline{v})>0$ to a level below zero at time $s$. This probability is known as

$$
\begin{aligned}
& 1-\pi(s-t, x-\underline{v}) \\
& =\Phi\left(\frac{(x-\underline{v})+m(s-t)}{\sigma \sqrt{(s-t)}}\right)-\exp \left(-\frac{2 m(x-\underline{v})}{\sigma^{2}}\right) \Phi\left(\frac{-(x-\underline{v})+m(s-t)}{\sigma \sqrt{(s-t)}}\right) .
\end{aligned}
$$

\section{A.1 Pricing the CDS}

A CDS is an insurance contract against credit events such as the default on a corporate bond (the reference obligation) by a specific issuer (reference entity). In case of a credit event, the seller of insurance is obligated to buy the reference obligation from the protection buyer at par. For this protection, the buyer pays a periodic premium to the protection seller until the maturity of the contract or the credit event, whichever comes first. Since the accrued premium must also be paid if a credit event occurs between two payment dates, the payments fit nicely into a continuous-time framework.

The present value of the premium payments can be calculated as

$$
E^{Q}\left(c \int_{0}^{T} \exp \left(-\int_{0}^{s} r_{u} d u\right) 1_{\{\tau>s\}} d s\right),
$$

where $c$ denotes the annual premium known as the CDS spread, $T$ the maturity of the contract, $r$ the risk-free interest rate, $\tau$ the default time of the obligor and 
$E^{Q}$ denotes the expectation under the risk-neutral pricing measure. Assuming independence between the default time and the risk-free interest rate, this can be written as

$$
c \int_{0}^{T} P(0, s) q(0, s) d s
$$

where $P(0, s)$ is the price of a default-free zero-coupon bond with maturity $s$, and $q(0, s)$ is the risk-neutral survival probability until time $s$ at the time of issuance, derived in equation (20).

Second, the present value of the credit protection is equal to

$$
E^{Q}\left((1-R) \exp \left(-\int_{0}^{\tau} r_{u} d u\right) 1_{\{\tau<T\}}\right)
$$

where $R$ is the recovery of bond market value measured as a percentage of par in the event of default. Maintaining the assumption of independence between the default time and the risk-free interest rate and assuming a constant $R$, this can be written as

$$
-(1-R) \int_{0}^{T} P(0, s) q^{\prime}(0, s) d s
$$

where $-q^{\prime}(0, t)=-d q(0, t) / d t$ is the probability density function of the default time. The CDS spread is determined such that the value of the contract is zero at initiation

$$
0=c \int_{0}^{T} P(0, s) q(0, s) d s+(1-R) \int_{0}^{T} P(0, s) q^{\prime}(0, s) d s,
$$

and hence

$$
c(0, T)=-\frac{(1-R) \int_{0}^{T} P(0, s) q^{\prime}(0, s) d s}{\int_{0}^{T} P(0, s) q(0, s) d s} .
$$

As mentioned, the model assumes a constant interest rate $r$, implying that

$$
c(0, T)=-\frac{(1-R) \int_{0}^{T} e^{-r s} q^{\prime}(0, s) d s}{\int_{0}^{T} e^{-r s} q(0, s) d s} .
$$

Integrating the denominator by parts yields

$$
c(0, T)=-r(1-R) \frac{\int_{0}^{T} e^{-r s} q^{\prime}(0, s) d s}{\left(1-e^{-r T} q(0, T)+\int_{0}^{T} e^{-r s} q^{\prime}(0, s) d s\right)} .
$$


$q^{\prime}(0, s)$ is found by differentiating equation (20) inside the integral. To ease notation, we denote $b=x-\underline{v}, g(x)=g\left(x \mid Y_{t}, z_{0}, t\right)$ and $t=0$, implying that a noise-free report is received one period before. Since $g(x)$ does not depend on $s$, we only need to differentiate $1-\pi(s, b)$ with respect to $s$ yielding

$$
\frac{\partial(1-\pi(s, b))}{\partial s}=\frac{-b}{\sigma \sqrt{2 \pi s^{3}}} \exp \left(-\frac{1}{2}\left(\frac{(b+m s)}{\sigma \sqrt{s}}\right)^{2}\right)=-f(x, s),
$$

where $f(x, s)$ is the first hitting time density of a Brownian motion with drift $m$ and volatility parameter $\sigma$. Therefore,

$$
q^{\prime}(0, s)=-\int_{\underline{v}}^{\infty} f(x, s) g(x) d x
$$

and hence

$$
\begin{aligned}
\int_{0}^{T} e^{-r s} q^{\prime}(0, s) d s & =-\int_{0}^{T} e^{-r s} \int_{\underline{v}}^{\infty} f(x, s) g(x) d x d s \\
& =-\int_{\underline{v}}^{\infty} g(x) \int_{0}^{T} e^{-r s} f(x, s) d s d x
\end{aligned}
$$

again since $g(x)$ does not depend on $s$. The inner integral $\int_{0}^{T} e^{-r s} f(x, s) d s$ is the integral of a discounted first hitting time density known from Reiner \& Rubinstein (1991) and Leland \& Toft (1996) in closed form as

$$
\begin{aligned}
G(x, T) & =\int_{0}^{T} e^{-r s} f(x, s) d s \\
& =\exp ((-c+z) b) \Phi\left(h_{1}(T)\right)+\exp ((-c-z) b) \Phi\left(h_{2}(T)\right),
\end{aligned}
$$

where

$$
\begin{gathered}
h_{1}(T)=\frac{\left(-b-z \sigma^{2} T\right)}{\sigma \sqrt{T}}, \\
h_{2}(T)=\frac{\left(-b+z \sigma^{2} T\right)}{\sigma \sqrt{T}}, \\
c=\frac{m}{\sigma^{2}},
\end{gathered}
$$

and

$$
z=\frac{\left(m^{2}+2 r \sigma^{2}\right)^{\frac{1}{2}}}{\sigma^{2}} .
$$

In the end, to calculate the CDS spread we only need to evaluate a single 
integral numerically

$$
\begin{aligned}
c(0, T) & =r(1-R) \frac{\int_{\underline{v}}^{\infty} G(x, T) g(x) d x}{1-e^{-r T} q(0, T)-\int_{\underline{v}}^{\infty} G(x, T) g(x) d x} \\
& =r(1-R) \frac{\int_{\underline{v}}^{\infty} G(x, T) g(x) d x}{1-e^{-r T} \int_{\underline{v}}^{\infty}(1-\pi(T, x-\underline{v})) g(x) d x-\int_{\underline{v}}^{\infty} G(x, T) g(x)(\underline{3} 8)}
\end{aligned}
$$

\section{B The Accounting Transparency Measure}

The basic idea in Berger et al. (2006) is that when pricing equity, investors perceive a firm's permanent earnings as a geometrically weighted average of reported earnings and industry average earnings. Investors put more weight on the firm's reported earnings when the accounting transparency is high.

Denote $\widetilde{E}_{j, t}$ as investors' perception of firm $j^{\prime} s$ permanent earnings in year $t, E_{j, t}$ as the firm's reported earnings and $E_{I, t}$ as the industry average earnings. Scaling the earnings by firm asset $A_{j, t}$ and industry assets $A_{I, t}$, the permanent earnings perceived by investors is formally written as

$$
\frac{\widetilde{E}_{j, t}}{A_{j, t-1}}=\left(\frac{E_{j, t}}{A_{j, t-1}}\right)^{\delta}\left(\frac{E_{I, t}}{A_{I, t-1}}\right)^{1-\delta},
$$

where $\delta \in[0,1]$ is the weight put on firm-specific information. Taking logarithms and first-order differences yields

$$
\widetilde{e}_{j, t}=\delta e_{j, t}+(1-\delta) e_{I, t}+(1-\delta)\left(\ln \left(\frac{A_{j, t-1}}{A_{I, t-1}}\right)-\ln \left(\frac{A_{j, t-2}}{A_{I, t-2}}\right)\right) .
$$

Lower case letters denote the log-growth rate of the variable $\widetilde{e}_{j, t}=\ln \left(\frac{\widetilde{E}_{j, t}}{\widetilde{E}_{j, t-1}}\right)$, $e_{j, t}=\ln \left(\frac{E_{j, t}}{E_{j, t-1}}\right), e_{I, t}=\ln \left(\frac{E_{I, t}}{E_{I, t-1}}\right)$ and $\frac{A_{j, t}}{A_{I, t}}$ represents the firm's share of the industry assets. Assuming this share does not change much from year $t-2$ to $t-1$, we approximately have

$$
\widetilde{e}_{j, t}=\delta e_{j, t}+(1-\delta) e_{I, t}
$$

The equity price $P_{j, t}$ is determined by investors' perception of permanent earnings, and with the assumption of a constant cost of capital $\mu_{j}$ and a constant 
expected growth rate $g_{j}$, we have

$$
P_{j, t}=\frac{\widetilde{E}_{j, t}}{\mu_{j}-g_{j}} .
$$

Hence, a firm's equity return equals it's permanent earnings growth rate $r_{j, t}=$ $\widetilde{e}_{j, t}$, implying that the idiosyncratic variance of the return must equal the idiosyncratic variance of the perceived permanent earnings. Idiosyncratic is defined relative to the industry, and the following relations between firm and industry returns and between firm and industry earnings, respectively, are assumed

$$
\begin{aligned}
& r_{j, t}=\widetilde{e}_{j, t}=\alpha^{r}+\beta r_{I, t}+\varepsilon_{j, t}^{r} \\
& e_{j, t}=a^{e}+b e_{I, t}+\varepsilon_{j, t}^{e} .
\end{aligned}
$$

Finally, using equations (41), (43) and (44), the idiosyncratic variance of the perceived earnings growth equals $\delta^{2}$ times the idiosyncratic variance of the reported earnings growth

$$
\operatorname{var}\left(\varepsilon_{j}^{r}\right)=\delta^{2} \operatorname{var}\left(\varepsilon_{j}^{e}\right),
$$

and the measure of accounting transparency $\delta$ is calculated as the idiosyncratic volatility of equity returns divided by the idiosyncratic volatility in earnings growth

$$
\delta=\frac{\operatorname{vol}\left(\varepsilon_{j}^{r}\right)}{\operatorname{vol}\left(\varepsilon_{j}^{e}\right)} .
$$




\section{References}

Abarbanell, J. \& Bernard, V. (2000), 'Is the U.S stock market myopic?', Journal of Accounting Research 38(2), 221-242.

Agrawal, D. \& Bohn, J. (2005), 'Humpbacks in credit spreads', Working Paper, Moody's KMV.

Berger, P. G., Chen, H. \& Li, F. (2006), 'Firm specific information and the cost of equity capital', Working Paper, Graduate School of Business, University of Chicago .

Berndt, A., Jarrow, R. \& Kang, C. (2006), 'Restructuring risk in credit default swaps: An empirical analysis', Working Paper, Carnegie Mellon and Cornell University .

Black, F. \& Cox, J. C. (1976), 'Valuing corporate securities: Some effects of bond indenture provisions', The Journal of Finance 31(2), 351-367.

Black, F. \& Scholes, M. (1973), 'The pricing of options and corporate liabilities', Journal of Political Economy 81, 637-654.

Blanco, R., Brennan, S. \& Marsh, I. W. (2005), 'An empirical analysis of the dynamic relation between investment-grade bonds and credit default swaps', The Journal of Finance 60(5), 2255-2281.

Campbell, J. \& Taksler, G. (2003), 'Equity volatility and corporate bond yields', The Journal of Finance 58(6), 2321-2349.

Cao, C., Yu, F. \& Zhong, Z. (2006), 'The information content of option-implied volatility for credit default swap valuation', Working Paper, Penn State and UC Irvine .

Collin-Dufresne, P., Goldstein, R. \& Martin, S. (2001), 'The determinants of credit spread changes', The Journal of Finance 56(6), 2177-2207.

Cremers, M., Driessen, J., Maenhout, P. \& Weinbaum, D. (2006), 'Individual stock-option prices and credit spreads', Working Paper, University of Amsterdam .

Delianedis, G. \& Geske, R. (2001), 'The components of corporate credit spreads: Default, recovery, tax, jumps, liquidity and market factors', Working Paper, UCLA Anderson School of Management. 
Duffee, G. (1998), 'The relation between treasury yields and corporate bond yield spreads', The Journal of Finance 53(6), 2225-2241.

Duffie, D. (1999), 'Credit default swap valuation', Financial Analysts Journal $\mathbf{5 5}, 73-87$.

Duffie, D. \& Lando, D. (2001), 'Term structures of credit spreads with incomplete accounting information', Econometrica 69(3), 633-664.

Elton, E. J., Gruber, M. J., Agrawal, D. \& Mann, C. (2001), 'Explaining the rate spread on corporate bonds', The Journal of Finance 56(1), 247-277.

Eom, Y. H., Helwege, J. \& Huang, J. (2004), 'Structural models of corporate bond pricing: An empirical analysis', The Review of Financial Studies 17(2), 4995443.

Ericsson, J., Jacobs, K. \& Oviedo, R. (2005), 'The determinants of credit default swap premia', Forthcoming, Journal of Financial and Quantitative Analysis .

Ericsson, J., Reneby, J. \& Wang, H. (2006), 'Can structural models price default risk? Evidence from bond and credit derivative markets', Working Paper, McGill University and Stockholm School of Economics .

Fama, E. F. \& MacBeth, J. (1973), 'Risk, return and equilibrium: Empirical tests', Journal of Political Economy 813, 607-636.

Fama, E. \& French, K. (1997), 'Industry costs of equity', Journal of Financial Economics 43, 153-193.

Fons, J. (1994), 'Using default rates to model the term structure of credit risk', Financial Analysts Journal 50, 25-32.

Güntay, L. \& Hackbarth, D. (2007), 'Corporate bond credit spreads and forecast dispersion', Working Paper, Indiana University and Washington University .

Helwege, J. \& Turner, C. (1999), 'The slope of the credit yield curve for speculativegrade issuers', The Journal of Finance 54(5), 1869-1884.

Houweling, P. \& Vorst, T. (2003), 'Pricing default swaps: Empirical evidence', Forthcoming, Journal of International Money and Finance .

Huang, J. \& Huang, M. (2003), 'How much of the corporate-treasury yield spread is due to credit risk?', Working Paper, Penn State and Stanford University . 
Huang, J. \& Zhou, H. (2007), 'Specification analysis of structural credit risk models', Working Paper, Penn State University .

Jones, E., Mason, S. \& Rosenfeld, E. (1984), 'Contingent claims analysis of corporate capital structures: An empirical investigation', Journal of Finance 39, 611-627.

Lando, D. \& Mortensen, A. (2005), 'Revisiting the slope of the credit curve', Journal of Investment Management 3(4), 6-32.

Leland, H. E. (1994), 'Corporate debt value, bond covenants, and optimal capital structure', The Journal of Finance 49(4), 1213-1252.

Leland, H. E. (2004), 'Predictions of default probabilities in structural models of debt', Journal of Investment Management 2(2).

Leland, H. E. \& Toft, K. B. (1996), 'Optimal capital structure, endogenous bankruptcy, and the term structure of credit spreads', The Journal of Finance 51(3), 987-1019.

Longstaff, F. A., Mithal, S. \& Neis, E. (2005), 'Corporate yield spreads: Default risk or liquidity? New evidence from the credit default swap market', The Journal of Finance 60(5), 2213-2253.

Longstaff, F. \& Schwartz, E. (1995), 'A simple approach to valuing risky fixed and floating rate debt', The Journal of Finance 50, 789-819.

Merton, R. C. (1974), 'On the pricing of corporate debt: The risk structure of interest rates', The Journal of Finance 29(2), 449-470.

Ogden, J. (1987), 'Determinants of the ratings and yield spreads on corporate bonds: Tests of the contingent claims model', Journal of Financial Research 10(4), 329-339.

Petersen, M. (2007), 'Estimating standard errors in finance panel data sets: Comparing approaches', Working Paper, Kellogg School of Management, Northwestern University .

Reiner, E. \& Rubinstein, M. (1991), 'Breaking down the barriers', Risk Magazine 4, 28-35. 
Sarga, O. \& Warga, A. (1989), 'Some empirical estimates of the risk structure of interest rates', The Journal of Finance 44, 1351-1360.

Sengupta, P. (1998), 'Corporate disclosure quality and the cost of debt', The Accounting Review 73(4), 459-474.

Verrecchia, R. (1983), 'Discretionary disclosure', Journal of Accounting and Economics 5, 179-194.

Yu, F. (2005), 'Accounting transparency and the term structure of credit spreads', Journal of Financial Economics 75(1), 53-84. 
Table 1: Summary Statistics of Accounting Transparency

This table reports summary statistics for the accounting transparency measure developed in Berger, Chen \& Li (2006) and calculated in section 3. Panel A represents statistics when pooling the measure across firms and years, while panel B displays statistics after averaging the measure in the time-series for each firm. In panel $\mathrm{A}, \mathrm{N}$ denotes the number of firm-years with sufficient data to calculate the accounting transparency measure and with associated CDS data. In panel $\mathrm{B}, \mathrm{N}$ denotes the number of unique firms.

\begin{tabular}{ccccccccc}
\hline $\mathrm{N}$ & Mean & Std.dev. & Min & $25 \%$ & $50 \%$ & $75 \%$ & $99 \%$ & Max \\
\hline \multicolumn{7}{c}{ Panel A. Statistics on the pooled transparency } & measure \\
890 & 0.50 & 0.61 & 0.00 & 0.16 & 0.29 & 0.60 & 3.23 & 5.65
\end{tabular}

Panel B. Statistics on the time-series average transparency measure

$\begin{array}{lllllllll}368 & 0.50 & 0.57 & 0.01 & 0.16 & 0.30 & 0.62 & 2.84 & 4.44\end{array}$

Table 2: Summary Statistics of Major Variables

This table reports averages of key variables across firms and time. The statistics are presented across the senior unsecured credit rating from Standard \& Poor's. The 5-year spread represents the overall spread level and is averaged over firms and end-of month observations. The volatility is calculated at month-end using 250 -days of historical equity returns. The associated leverage is total liabilities divided by the sum of total liabilities and equity market capitalization. The accounting transparency measure is developed in Berger, Chen \& Li (2006) and calculated in section 3. NR means not rated.

\begin{tabular}{lcccc}
\hline & 5yr spread & Volatility & Leverage & Transparency \\
\hline AAA & 23 & 0.29 & 0.28 & 0.92 \\
AA & 26 & 0.28 & 0.21 & 0.88 \\
A & 48 & 0.33 & 0.34 & 0.60 \\
BBB & 128 & 0.36 & 0.49 & 0.40 \\
BB & 392 & 0.49 & 0.61 & 0.39 \\
B & 658 & 0.74 & 0.76 & 0.20 \\
NR & 137 & 0.33 & 0.31 & 0.66 \\
\hline
\end{tabular}




\section{Table 3: Average Correlations Among Major Variables}

This table reports the Spearman rank correlation coefficients between the major variables. The correlations are calculated each month, and the resulting average correlations are reported. The volatility is calculated at month-end using 250-days of historical equity returns. The associated leverage is total liabilities divided by the sum of total liabilities and equity market capitalization. The accounting transparency measure is developed in Berger, Chen \& Li (2006) and calculated in section 3. The senior unsecured credit ratings from Standard \& Poor's are transformed to a numerical scale, where firms rated AAA are assigned the highest number, AA the next highest and so forth.

\begin{tabular}{lcccc}
\hline & $5 y r$ spread & Volatility & Leverage & Transp \\
\hline Volatility & 0.57 & & & \\
Leverage & 0.62 & 0.25 & & \\
Transp. & -0.11 & -0.08 & -0.16 & \\
Rating & -0.76 & -0.41 & -0.55 & 0.16 \\
\hline
\end{tabular}


Table 4: Summary Statistics by Credit Rating and Maturity

This table illustrates the distribution of month-end CDS quotes across credit ratings and maturities. The mean consensus quote across time and firms is found in the first row for each rating category, while the number of observations and the mean relative quote dispersion are found in the second and third row, respectively. The latter is calculated as the standard deviation of collected quotes divided by the consensus quote. Panel A reports the statistics for unrestricted curves, while Panel B reports statistics for full curves with an observation at a maturity of $1,3,5,7$ and 10 years.

\begin{tabular}{|c|c|c|c|c|c|c|}
\hline & $1 \mathrm{yr}$ & $3 \mathrm{yr}$ & $5 y \mathrm{r}$ & $7 \mathrm{yr}$ & $10 \mathrm{yr}$ & Total \\
\hline \multicolumn{7}{|c|}{ Panel A. Unrestricted curves } \\
\hline \multirow{3}{*}{ AAA } & 24 & 25 & 25 & 33 & 38 & 29 \\
\hline & 34 & 59 & 92 & 66 & 45 & 296 \\
\hline & 0.13 & 0.13 & 0.13 & 0.13 & 0.13 & 0.13 \\
\hline \multirow[t]{3}{*}{$\mathrm{AA}$} & 24 & 24 & 26 & 29 & 35 & 28 \\
\hline & 146 & 264 & 351 & 297 & 226 & 1,284 \\
\hline & 0.14 & 0.14 & 0.12 & 0.12 & 0.13 & 0.13 \\
\hline \multirow[t]{3}{*}{ A } & 45 & 44 & 48 & 52 & 59 & 50 \\
\hline & 1,177 & 1,930 & 2,136 & 1,856 & 1,658 & 8,757 \\
\hline & 0.14 & 0.12 & 0.09 & 0.11 & 0.12 & 0.11 \\
\hline \multirow[t]{3}{*}{ BBB } & 131 & 126 & 128 & 127 & 131 & 128 \\
\hline & 1,732 & 2,568 & 2,736 & 2,365 & 2,234 & 11,635 \\
\hline & 0.13 & 0.11 & 0.08 & 0.09 & 0.11 & 0.10 \\
\hline \multirow[t]{3}{*}{$\mathrm{BB}$} & 419 & 407 & 392 & 390 & 368 & 395 \\
\hline & 449 & 702 & 757 & 559 & 567 & 3,034 \\
\hline & 0.11 & 0.10 & 0.09 & 0.09 & 0.10 & 0.10 \\
\hline \multirow[t]{3}{*}{ B } & 761 & 712 & 658 & 613 & 615 & 672 \\
\hline & 66 & 82 & 87 & 76 & 70 & 381 \\
\hline & 0.12 & 0.11 & 0.08 & 0.09 & 0.10 & 0.10 \\
\hline \multirow[t]{3}{*}{ NR } & 142 & 137 & 137 & 184 & 183 & 154 \\
\hline & 31 & 53 & 55 & 35 & 38 & 212 \\
\hline & 0.10 & 0.11 & 0.09 & 0.09 & 0.07 & 0.09 \\
\hline \multirow[t]{3}{*}{ Total } & 141 & 136 & 133 & 129 & 139 & \\
\hline & 3,635 & 5,658 & 6,214 & 5,254 & 4,838 & \\
\hline & 0.13 & 0.12 & 0.09 & 0.10 & 0.11 & \\
\hline
\end{tabular}




\section{Table 4: Summary Statistics by Credit Rating and Maturity (cont.)}

This table illustrates the distribution of month-end CDS quotes across credit ratings and maturities. The mean consensus quote across time and firms is found in the first row for each rating category, while the number of observations and the mean relative quote dispersion are found in the second and third row, respectively. The latter is calculated as the standard deviation of collected quotes divided by the consensus quote. Panel A reports the statistics for unrestricted curves, while Panel B reports statistics for full curves with an observation at a maturity of $1,3,5,7$ and 10 years.

\begin{tabular}{|c|c|c|c|c|c|c|}
\hline & $1 \mathrm{yr}$ & $3 y r$ & $5 y \mathrm{r}$ & $7 \mathrm{yr}$ & $10 \mathrm{yr}$ & Total \\
\hline \multicolumn{7}{|c|}{ Panel B. Full curves } \\
\hline \multirow{3}{*}{ AAA } & 33 & 44 & 54 & 56 & 61 & 49 \\
\hline & 18 & 18 & 18 & 18 & 18 & 90 \\
\hline & 0.14 & 0.12 & 0.09 & 0.11 & 0.12 & 0.12 \\
\hline \multirow[t]{3}{*}{$\mathrm{AA}$} & 28 & 35 & 39 & 41 & 46 & 38 \\
\hline & 94 & 94 & 94 & 94 & 94 & 470 \\
\hline & 0.14 & 0.13 & 0.10 & 0.11 & 0.12 & 0.12 \\
\hline \multirow[t]{3}{*}{ A } & 48 & 55 & 60 & 63 & 69 & 59 \\
\hline & 893 & 893 & 893 & 893 & 893 & 4,465 \\
\hline & 0.14 & 0.12 & 0.09 & 0.11 & 0.12 & 0.12 \\
\hline \multirow[t]{3}{*}{ BBB } & 133 & 140 & 143 & 144 & 146 & 142 \\
\hline & 1,428 & 1,428 & 1,428 & 1,428 & 1,428 & 7,140 \\
\hline & 0.13 & 0.11 & 0.07 & 0.09 & 0.11 & 0.10 \\
\hline \multirow[t]{3}{*}{ BB } & 428 & 425 & 413 & 403 & 390 & 412 \\
\hline & 342 & 342 & 342 & 342 & 342 & 1,710 \\
\hline & 0.11 & 0.10 & 0.08 & 0.08 & 0.10 & 0.10 \\
\hline \multirow[t]{3}{*}{ B } & 690 & 690 & 668 & 642 & 626 & 663 \\
\hline & 50 & 50 & 50 & 50 & 50 & 250 \\
\hline & 0.12 & 0.10 & 0.08 & 0.09 & 0.10 & 0.10 \\
\hline \multirow[t]{3}{*}{ NR } & 210 & 219 & 219 & 231 & 222 & 220 \\
\hline & 12 & 12 & 12 & 12 & 12 & 60 \\
\hline & 0.10 & 0.10 & 0.08 & 0.08 & 0.08 & 0.09 \\
\hline \multirow[t]{3}{*}{ Total } & 148 & 154 & 155 & 155 & 157 & \\
\hline & 2,837 & 2,837 & 2,837 & 2,837 & 2,837 & \\
\hline & 0.13 & 0.11 & 0.08 & 0.10 & 0.11 & \\
\hline
\end{tabular}


Table 5: Estimation of the Term Structure of Transparency Spreads This table reports the results of monthly cross-sectional regressions when estimating the gap between high and low transparency CDS spread curves. The coefficient estimates are averaged in the time-series. T-statistics are reported in parentheses and are based on the standard error in Fama \& MacBeth (1973). $d$ is a dummy variable equal to 1 if the transparency measure developed in Berger, Chen \& $\operatorname{Li}(2006)$ and calculated in section 3 in a given year ranks above the median score. $m_{T}$ is a variable that attains a value equal to the CDS contract maturity $T$. The regression coefficient in front of the product $d m_{T}$ can be directly interpreted as the transparency spread. The volatility is calculated using 250 days of historical equity returns, and leverage is total liabilities divided by the sum of total liabilities and equity market capitalization. Quote dispersion is the standard deviation of collected quotes divided by the consensus quote. Full curves are a restricted set of curves with an observation at a maturity of $1,3,5,7$ and 10 years. The monthly regressions are Spread $_{i t}=\beta_{1 t} m_{1 i t}+\beta_{2 t} m_{3 i t}+\beta_{3 t} m_{5 i t}+\beta_{4 t} m_{7 i t}+\beta_{5 t} m_{10 i t}+\beta_{6 t} d m_{1 i t}+$ $\beta_{7 t} d m_{3 i t}+\beta_{8 t} d m_{5 i t}+\beta_{9 t} d m_{7 i t}+\beta_{10 t} d m_{10 i t}+\beta_{11 t} V o l_{i t}+\beta_{12 t} L e v_{i t}+\beta_{13 t} Q d i s p_{i t}+\varepsilon_{i t}$. $*, * *$ and ${ }^{* * *}$ denote significance at 10,5 and 1 percent, respectively.

\begin{tabular}{|c|c|c|c|c|}
\hline & (1) & $(2)$ & (3) & (4) \\
\hline & Unrestr. & Unrestr. & Full curves & Full curves \\
\hline \multirow[t]{2}{*}{$\mathrm{m}_{1}$} & $-293.64^{* * *}$ & $-299.10^{* * *}$ & $-315.01^{* * *}$ & $-333.24^{* * *}$ \\
\hline & $(-11.21)$ & $(-12.78)$ & $(-11.48)$ & $(-13.84)$ \\
\hline \multirow[t]{2}{*}{$\mathrm{m}_{3}$} & $-292.11^{* * *}$ & $-297.06^{* * *}$ & $-312.26^{* * *}$ & $-328.17^{* * *}$ \\
\hline & $(-11.17)$ & $(-12.66)$ & $(-10.78)$ & $(-12.54)$ \\
\hline \multirow[t]{2}{*}{$\mathrm{m}_{5}$} & $-293.64^{* * *}$ & $-297.26^{* * *}$ & $-316.80^{* * *}$ & $-328.18^{* * *}$ \\
\hline & $(-10.87)$ & $(-11.94)$ & $(-10.82)$ & $(-12.00)$ \\
\hline \multirow[t]{2}{*}{$\mathrm{m}_{7}$} & $-296.34^{* * *}$ & $-300.50^{* * *}$ & $-315.20^{* * *}$ & $-328.85^{* * *}$ \\
\hline & $(-10.74)$ & $(-11.87)$ & $(-10.36)$ & $(-11.74)$ \\
\hline \multirow[t]{2}{*}{$\mathrm{m}_{10}$} & $-295.43^{* * *}$ & $-300.12^{* * *}$ & $-311.45^{* * *}$ & $-327.26^{* * *}$ \\
\hline & $(-10.37)$ & $(-11.55)$ & $(-9.90)$ & $(-11.44)$ \\
\hline \multirow[t]{2}{*}{$\mathrm{dm}_{1}$} & $-22.66^{* * *}$ & $-22.35^{* * *}$ & $-23.56^{* * *}$ & $-24.31^{* * *}$ \\
\hline & $(-4.22)$ & $(-4.11)$ & $(-3.91)$ & $(-4.29)$ \\
\hline \multirow[t]{2}{*}{$\mathrm{dm}_{3}$} & $-20.04^{* * *}$ & $-19.98^{* * *}$ & $-20.52^{* * *}$ & $-20.94^{* * *}$ \\
\hline & $(-6.58)$ & $(-6.44)$ & $(-3.57)$ & $(-3.67)$ \\
\hline \multirow[t]{2}{*}{$\mathrm{dm}_{5}$} & $-13.15^{* * *}$ & $-13.24^{* * *}$ & $-17.61^{* * *}$ & $-18.18^{* * *}$ \\
\hline & $(-5.56)$ & $(-5.54)$ & $(-3.11)$ & $(-3.21)$ \\
\hline \multirow[t]{2}{*}{$\mathrm{dm}_{7}$} & $-12.88^{* * *}$ & $-13.05^{* * *}$ & $-14.67^{* *}$ & $-15.78^{* * *}$ \\
\hline & $(-5.98)$ & $(-5.75)$ & $(-2.71)$ & $(-2.82)$ \\
\hline \multirow[t]{2}{*}{$\mathrm{dm}_{10}$} & $-10.94^{* * *}$ & $-10.82^{* * *}$ & $-13.08^{* *}$ & $-14.06^{* *}$ \\
\hline & $(-5.26)$ & $(-5.21)$ & $(-2.47)$ & $(-2.59)$ \\
\hline \multirow[t]{2}{*}{ Volatility } & $805.44^{* * *}$ & $805.59^{* * *}$ & $873.06^{* * *}$ & $874.86^{* * *}$ \\
\hline & $(16.50)$ & $(16.53)$ & $(12.92)$ & $(12.99)$ \\
\hline \multirow[t]{2}{*}{ Leverage } & $317.20^{* * *}$ & $318.99^{* * *}$ & $315.71^{* * *}$ & $321.00^{* * *}$ \\
\hline & $(12.98)$ & $(13.14)$ & $(11.80)$ & $(12.29)$ \\
\hline \multirow[t]{2}{*}{ Qdisp } & -33.37 & & $-122.68^{* *}$ & \\
\hline & $(-1.07)$ & & $(-2.37)$ & \\
\hline
\end{tabular}


Table 6: Estimation of the Term Structure of Transparency Spreads for High and Low Risk Firms

This table reports the results of monthly cross-sectional regressions when estimating the gap between high and low transparency CDS spread curves. The coefficient estimates are averaged in the time-series. T-statistics are reported in parentheses and are based on the standard error in Fama \& MacBeth (1973). $d$ is a dummy variable equal to 1 if the transparency measure developed in Berger, Chen \& Li (2006) and calculated in section 3 in a given year ranks above the median score. $m_{T}$ is a variable that attains a value equal to the CDS contract maturity $T$. The regression coefficient in front of the product $d m_{T}$ can be directly interpreted as the transparency spread. The volatility is calculated using 250 days of historical equity returns, and leverage is total liabilities divided by the sum of total liabilities and equity market capitalization. Quote dispersion is the standard deviation of collected quotes divided by the consensus quote. Full curves are a restricted set of curves with an observation at a maturity of $1,3,5,7$ and 10 years. The monthly regressions are Spread $_{i t}=\beta_{1 t} m_{1 i t}+\beta_{2 t} m_{3 i t}+\beta_{3 t} m_{5 i t}+\beta_{4 t} m_{7 i t}+\beta_{5 t} m_{10 i t}+\beta_{6 t} d m_{1 i t}+$ $\beta_{7 t} d m_{3 i t}+\beta_{8 t} d m_{5 i t}+\beta_{9 t} d m_{7 i t}+\beta_{10 t} d m_{10 i t}+\beta_{11 t} V o l_{i t}+\beta_{12 t} L e v_{i t}+\beta_{13 t} Q d i s p_{i t}+\varepsilon_{i t}$. Each month, the firms are separated into high and low leverage and volatility groups by the respective medians. The regression is then performed for each group. *,** and *** denote significance at 10,5 and 1 percent, respectively.

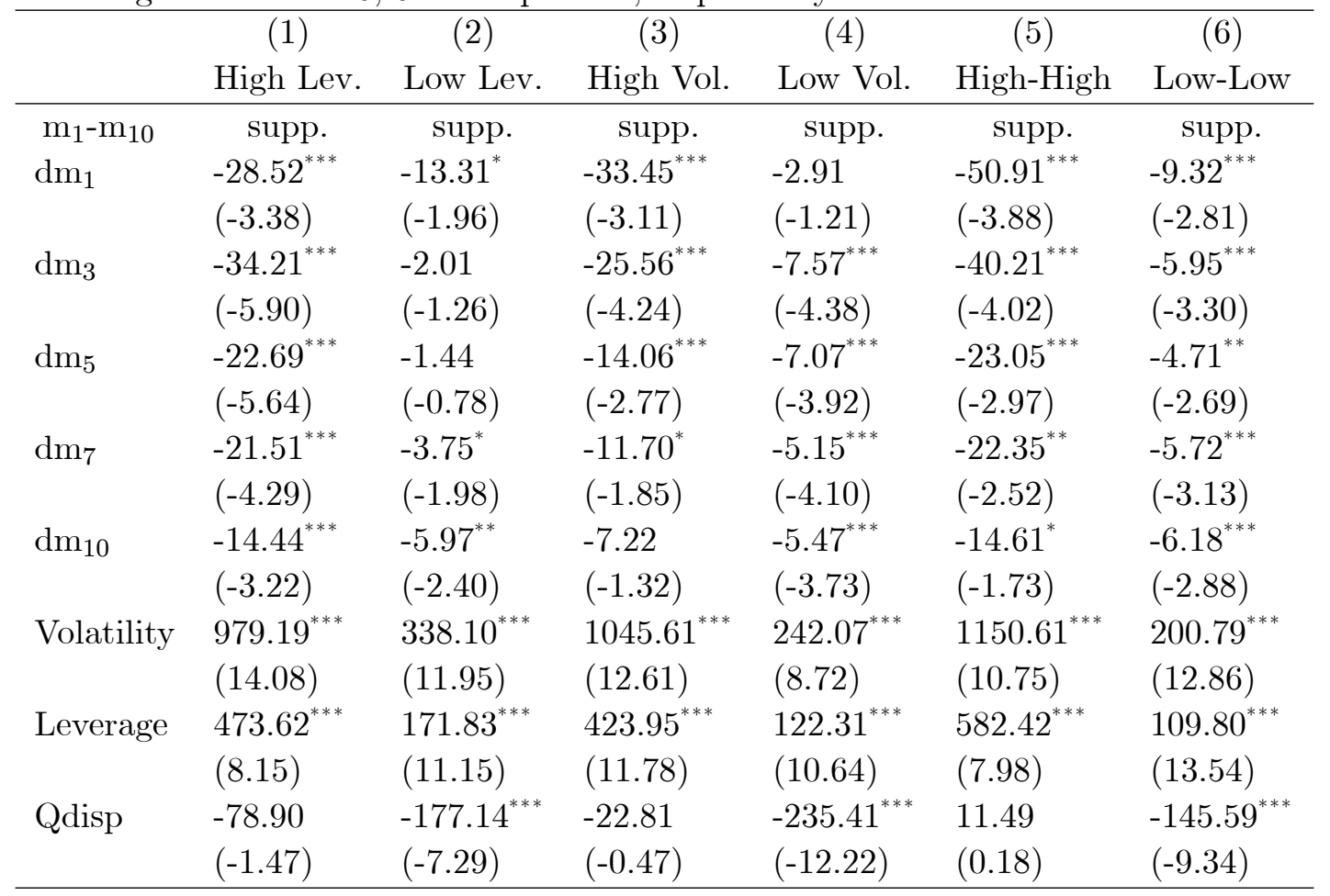




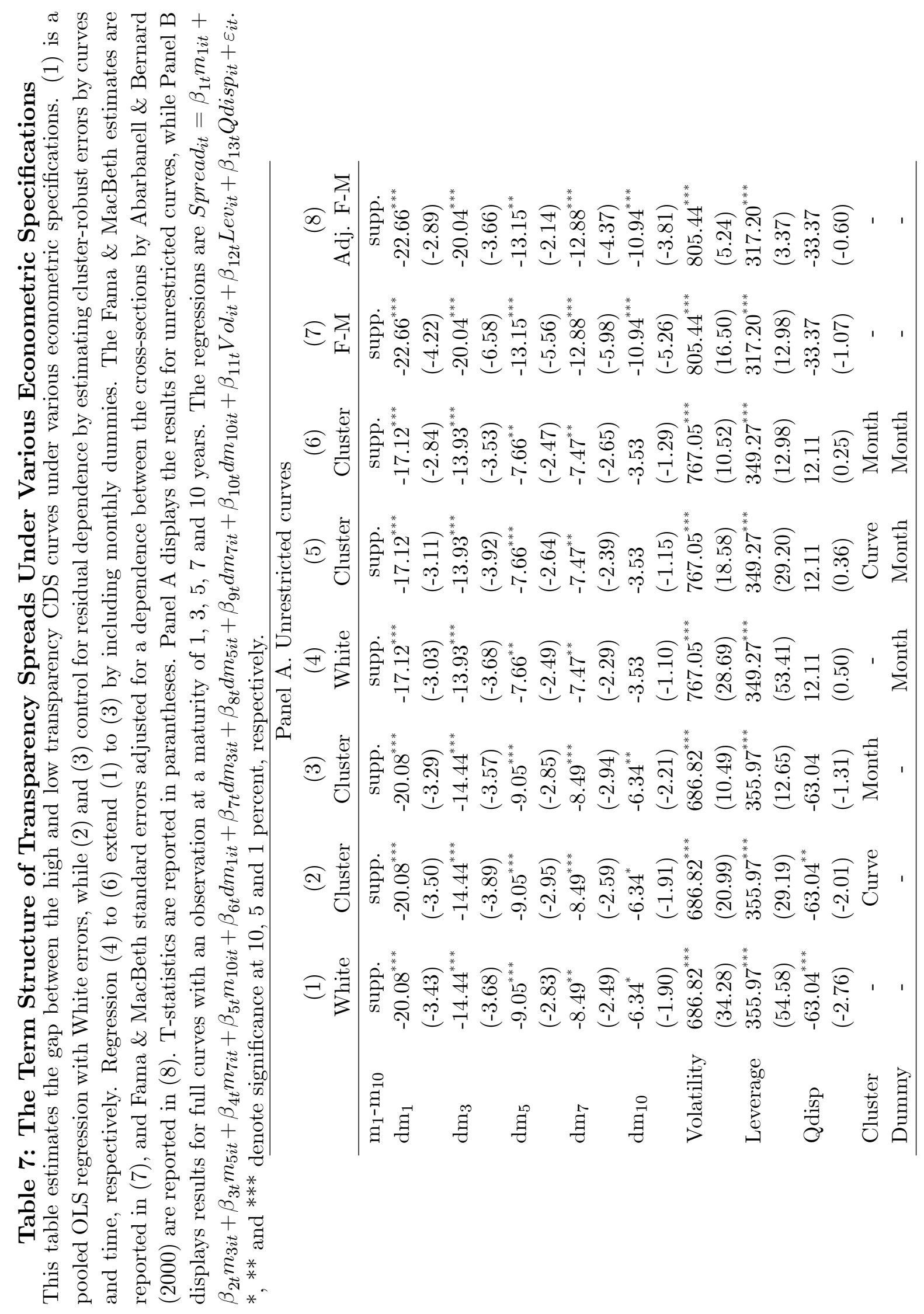




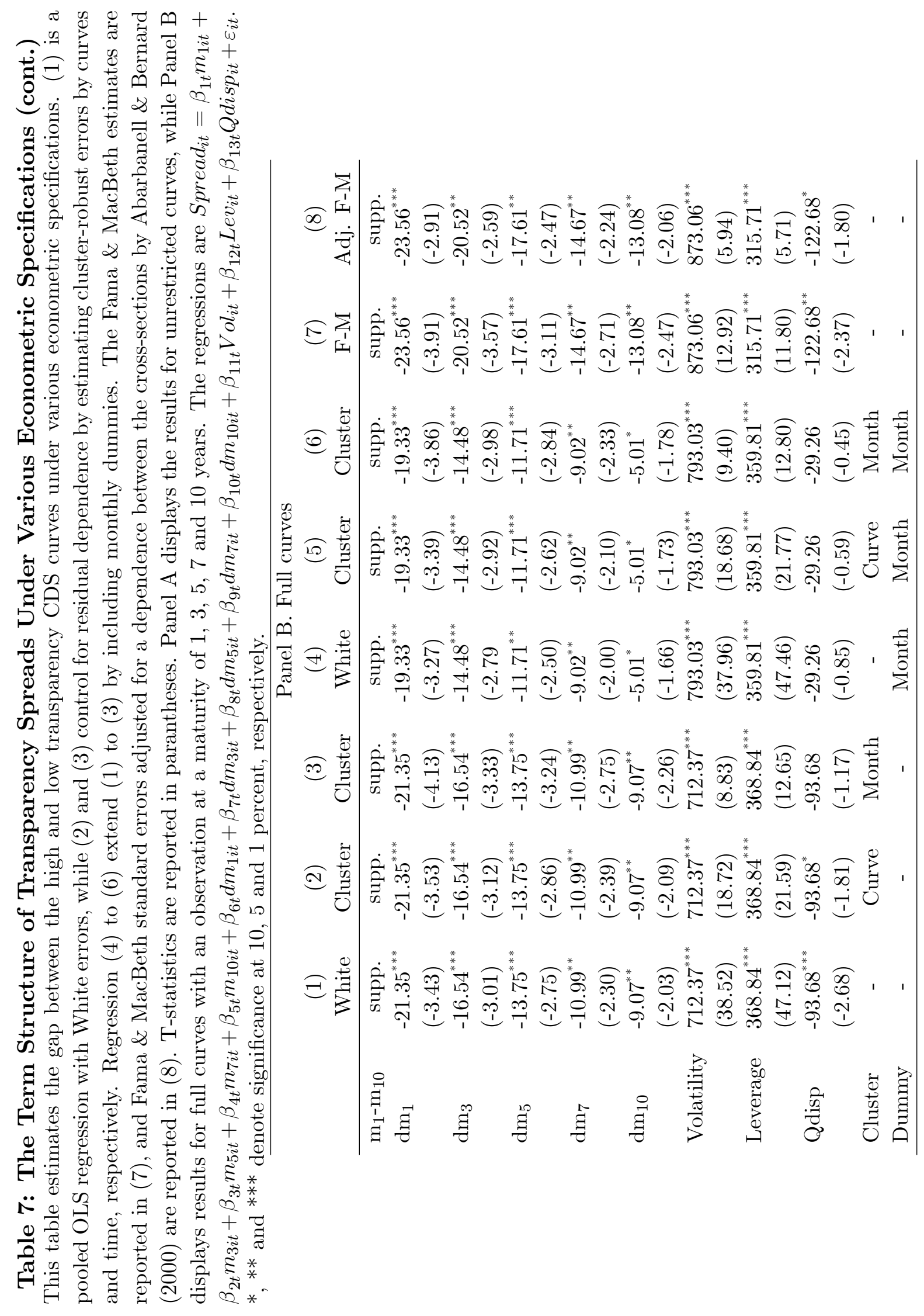




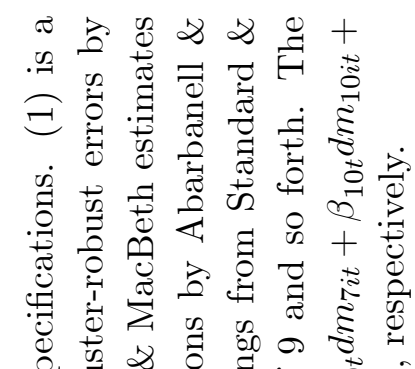

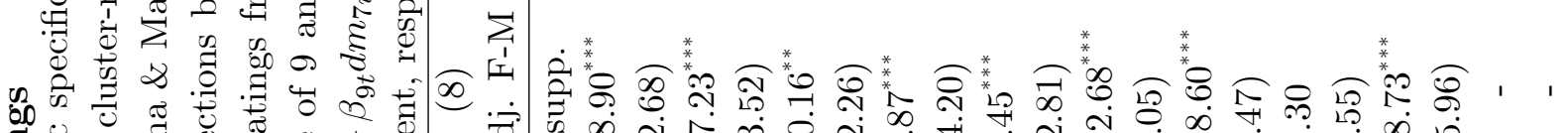

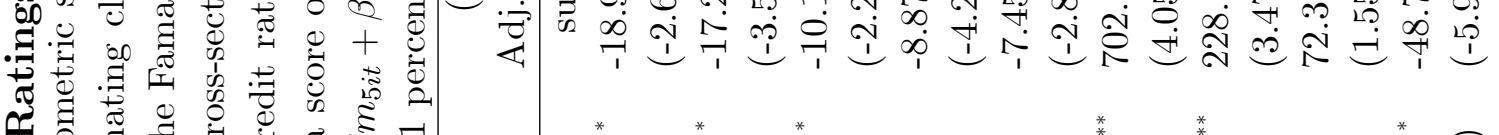

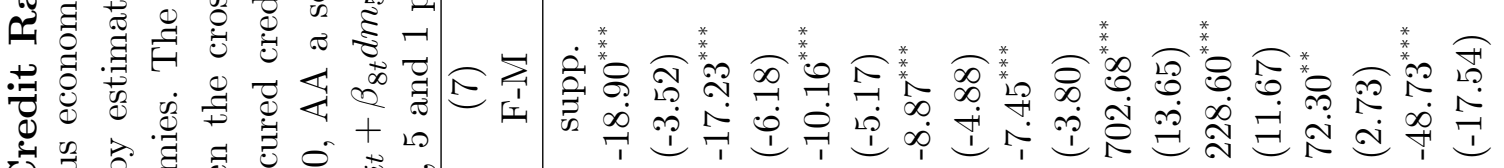

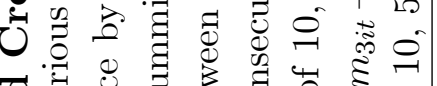

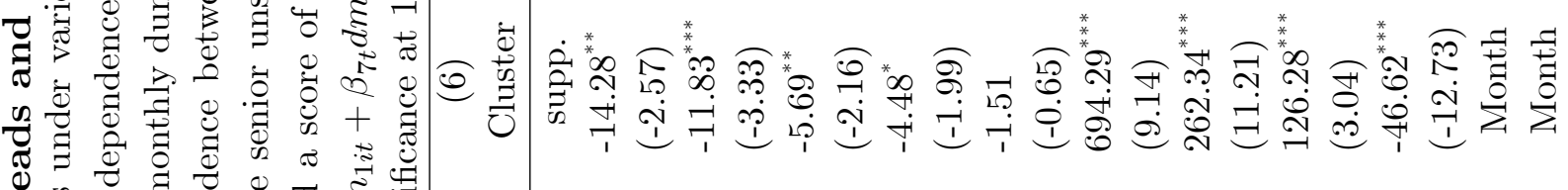

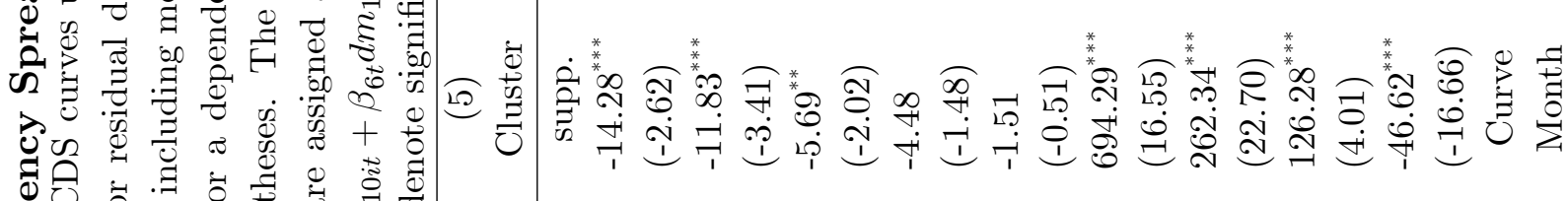

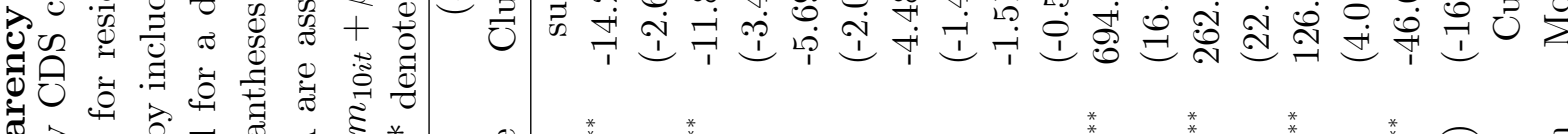

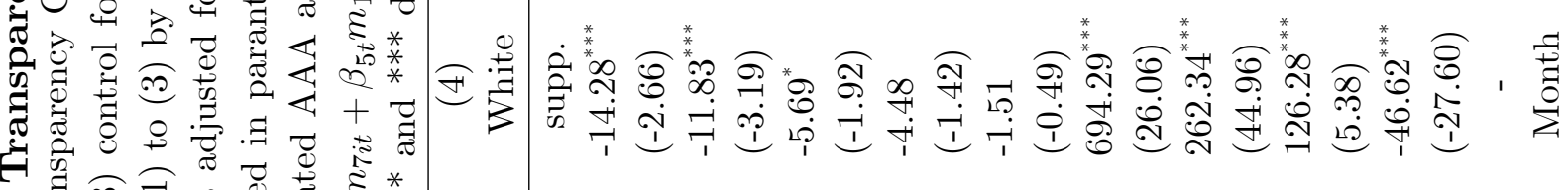

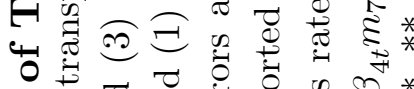

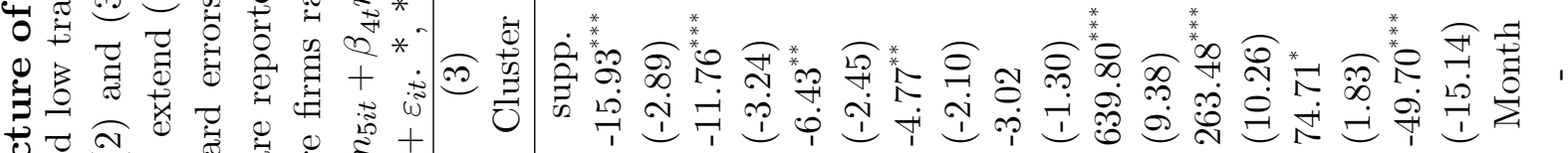

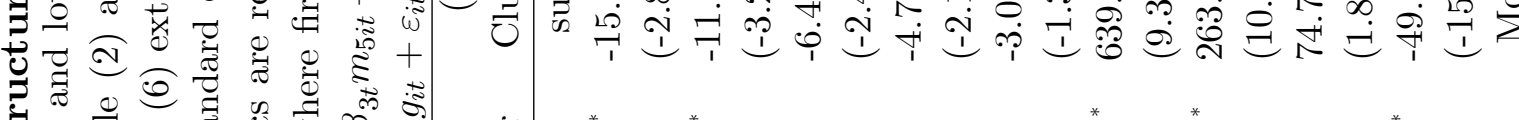

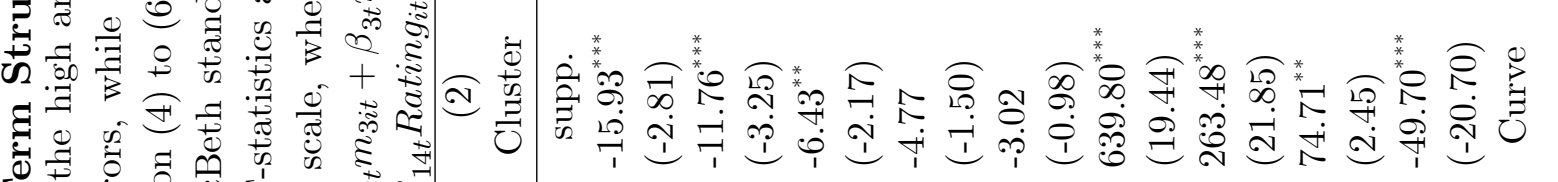

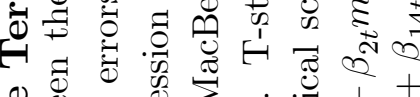

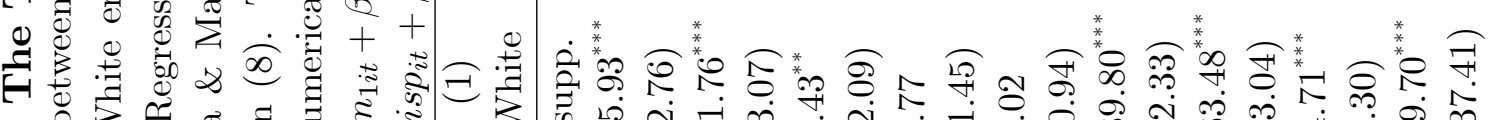

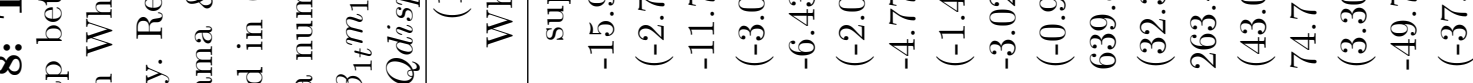
$\infty$ 论

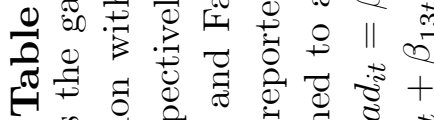
की 苛

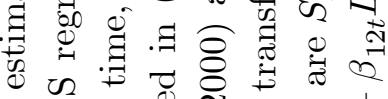

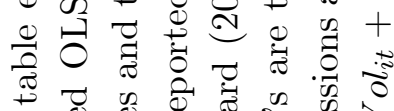

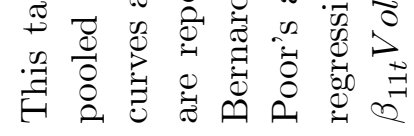

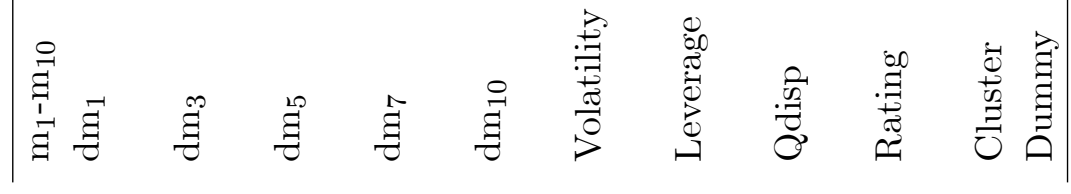


Table 9: The Term Structure of Transparency Spreads and the Yield Curve

This table estimates the gap between the high and low transparency CDS curves under various econometric specifications. (1) is a pooled OLS regression with White errors, while (2) and (3) control for residual dependence by estimating cluster-robust errors by curves and time, respectively. T-statistics are reported in parantheses. The senior unsecured credit ratings from Standard \& Poor's are transformed to a numerical scale, where firms rated AAA are assigned a score of 10, AA a score of 9 and so forth. The slope of the yield curve is the difference between the 10 and 1-year constant maturity treasury rates. Panel A displays the results for unrestricted curves, while Panel B displays results for full curves with an observation at a maturity of $1,3,5,7$ and 10 years. The regressions are Spread $_{i t}=\beta_{1 t} m_{1 i t}+\beta_{2 t} m_{3 i t}+\beta_{3 t} m_{5 i t}+\beta_{4 t} m_{7 i t}+\beta_{5 t} m_{10 i t}+\beta_{6 t} d m_{1 i t}+\beta_{7 t} d m_{3 i t}+$ $\beta_{8 t} d m_{5 i t}+\beta_{9 t} d m_{7 i t}+\beta_{10 t} d m_{10 i t}+\beta_{11 t}$ Vol $_{i t}+\beta_{12 t}$ Lev $_{i t}+\beta_{13 t}$ Qdisp $_{i t}+\beta_{14 t}$ Rating $_{i t}+$ $\beta_{15 t}$ Slope $_{i t}+\varepsilon_{i t} .{ }^{*},{ }^{* *}$ and ${ }^{* * *}$ denote significance at 10,5 and 1 percent, respectively.

Panel A. Unrestricted curves

\begin{tabular}{|c|c|c|c|c|c|c|}
\hline & & & & \\
\hline & $(1)$ & $(2)$ & $(3)$ & $(1)$ & $(2)$ & $(3)$ \\
\hline & White & Cluster & Cluster & White & Cluster & Cluster \\
\hline \multirow{3}{*}{$\begin{array}{l}\mathrm{m}_{1}-\mathrm{m}_{10} \\
\mathrm{dm}_{1}\end{array}$} & supp. & supp. & supp. & supp. & supp. & supp. \\
\hline & $-15.48^{* * *}$ & $-15.48^{* * *}$ & $-15.48^{* * *}$ & $-13.93^{* *}$ & $-13.93^{* *}$ & $-13.93^{* * *}$ \\
\hline & $(-2.70)$ & $(-2.75)$ & $(-2.77)$ & $(-2.30)$ & $(-2.35)$ & $(-3.16)$ \\
\hline \multirow[t]{2}{*}{$\mathrm{dm}_{3}$} & $-11.60^{* * *}$ & $-11.60^{* * *}$ & $-11.60^{* * *}$ & $-9.02^{*}$ & $-9.02^{*}$ & $-9.02^{* *}$ \\
\hline & $(-3.05)$ & $(-3.23)$ & $(-3.20)$ & $(-1.72)$ & $(-1.78)$ & $(-2.13)$ \\
\hline \multirow[t]{2}{*}{$\mathrm{dm}_{5}$} & $-6.27^{* *}$ & $-6.27^{* *}$ & $-6.27^{* *}$ & -6.22 & -6.22 & $-6.22^{*}$ \\
\hline & $(-2.05)$ & $(-2.14)$ & $(-2.37)$ & $(-1.33)$ & $(-1.38)$ & $(-1.72)$ \\
\hline \multirow[t]{2}{*}{$\mathrm{dm}_{7}$} & -4.68 & -4.68 & $-4.68^{* *}$ & -3.76 & -3.76 & -3.76 \\
\hline & $(-1.43)$ & $(-1.49)$ & $(-2.05)$ & $(-0.84)$ & $(-0.87)$ & $(-1.10)$ \\
\hline \multirow[t]{2}{*}{$\mathrm{dm}_{10}$} & -2.89 & -2.89 & -2.89 & -1.50 & -1.50 & -1.50 \\
\hline & $(-0.91)$ & $(-0.95)$ & $(-1.23)$ & $(-0.36)$ & $(-0.37)$ & $(-0.42)$ \\
\hline \multirow[t]{2}{*}{ Volatility } & $649.90^{* * *}$ & $649.90^{* * *}$ & $649.90^{* * *}$ & $682.60^{* * *}$ & $682.60^{* * *}$ & $682.60^{* * *}$ \\
\hline & $(32.52)$ & $(19.57)$ & $(9.56)$ & $(35.31)$ & $(17.12)$ & $(7.99)$ \\
\hline \multirow[t]{2}{*}{ Leverage } & $263.51^{* * *}$ & $263.51^{* * *}$ & $263.51^{* * *}$ & $270.80^{* * *}$ & $270.80^{* * *}$ & $270.80^{* * *}$ \\
\hline & $(43.31)$ & $(22.04)$ & $(10.83)$ & $(34.71)$ & $(15.91)$ & $(10.58)$ \\
\hline \multirow[t]{2}{*}{ Qdisp } & $94.90^{* * *}$ & $94.90^{* * *}$ & $94.90^{* *}$ & $75.96^{* *}$ & 75.96 & 75.96 \\
\hline & $(4.18)$ & $(3.09)$ & $(2.29)$ & $(2.25)$ & $(1.54)$ & $(1.13)$ \\
\hline \multirow[t]{2}{*}{ Rating } & $-49.38^{* * *}$ & $-49.38^{* * *}$ & $-49.38^{* * *}$ & $-57.97^{* * *}$ & $-57.97^{* * *}$ & $-57.97^{* * *}$ \\
\hline & $(-37.37)$ & $(-20.74)$ & $(-13.66)$ & $(-35.79)$ & $(-16.72)$ & $(-13.58)$ \\
\hline \multirow[t]{2}{*}{ Slope } & $-0.51^{* * *}$ & $-0.51^{* * *}$ & $-0.51^{* * *}$ & $-0.65^{* * *}$ & $-0.65^{* * *}$ & $-0.65^{* * *}$ \\
\hline & $(-22.26)$ & $(-11.09)$ & $(-3.19)$ & $(-18.99)$ & $(-8.89)$ & $(-2.82)$ \\
\hline Cluster & - & Curve & Month & - & Curve & Month \\
\hline Dummy & - & - & - & - & - & - \\
\hline
\end{tabular}

Panel B. Full curves 


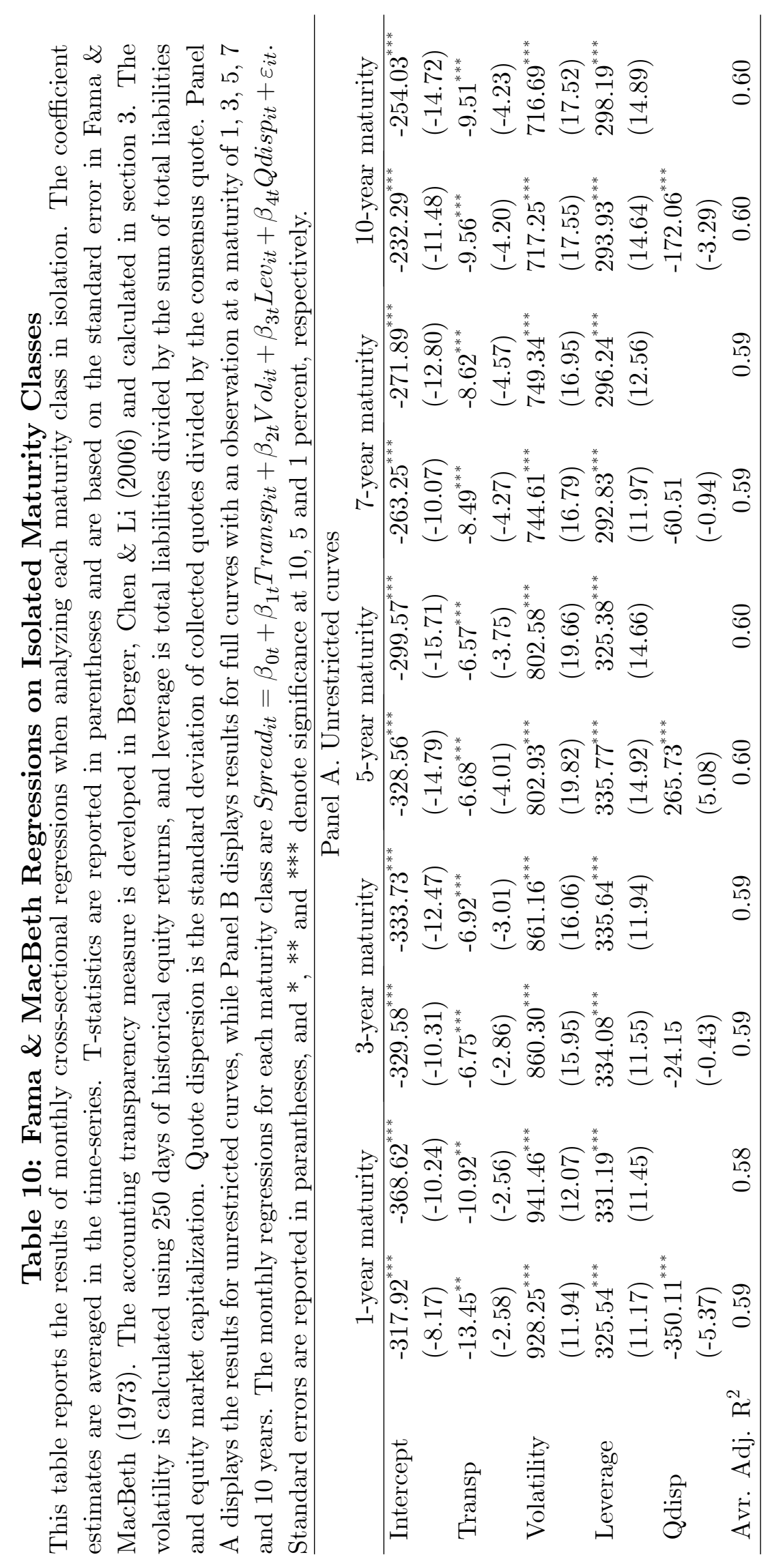




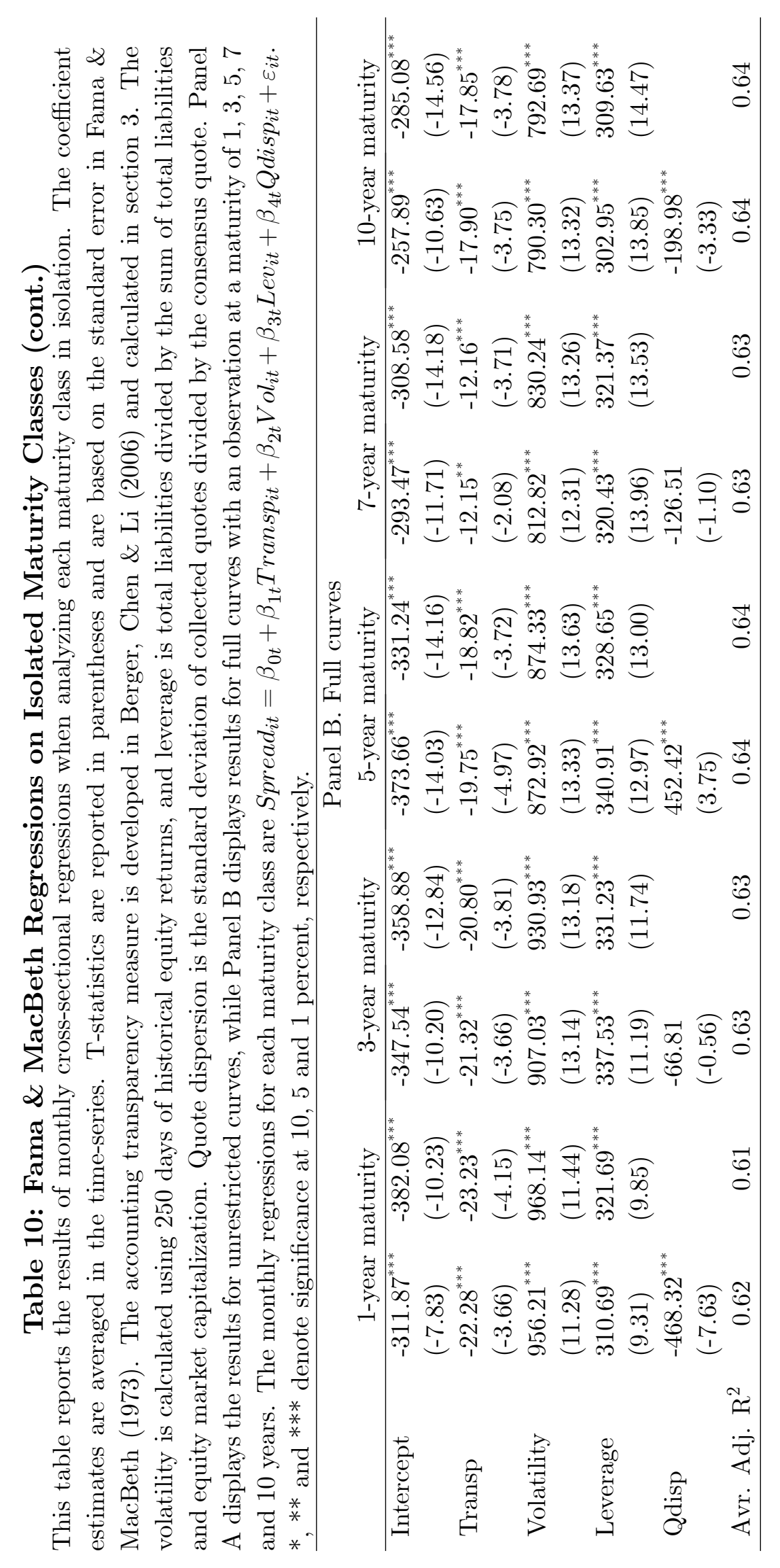


苞» bo:

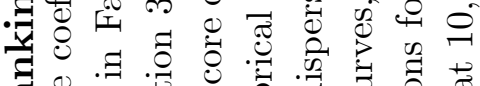

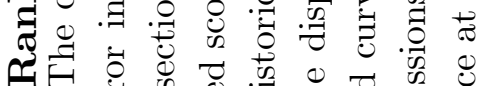

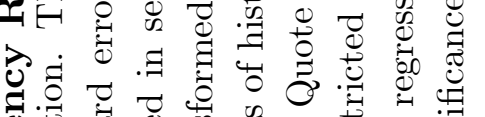

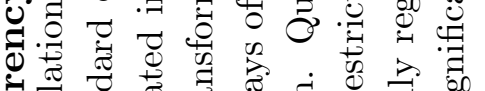

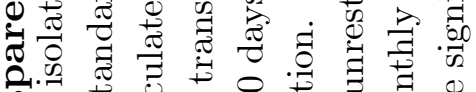
牙.

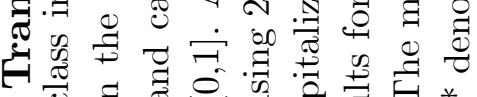

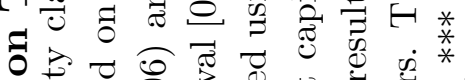

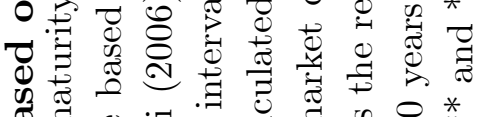

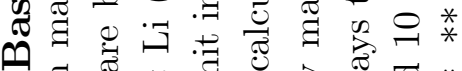
的㐘 记 औ.

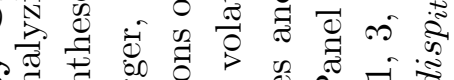

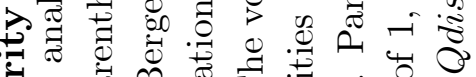

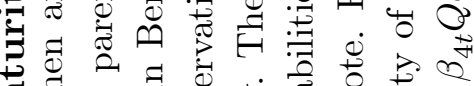

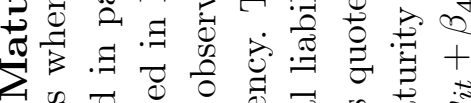

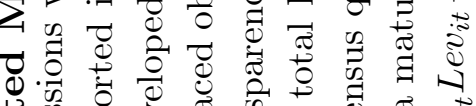

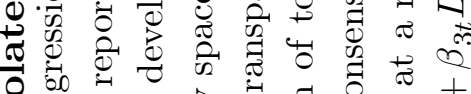

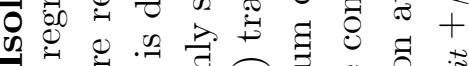

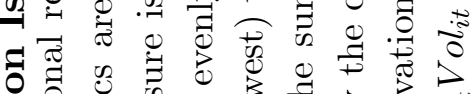

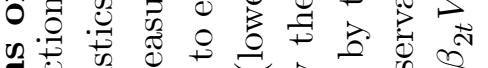

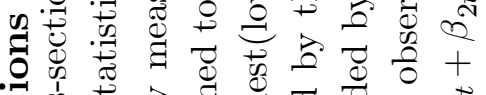
W

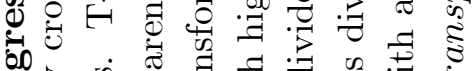
ơ

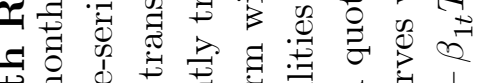

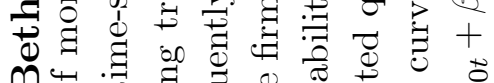

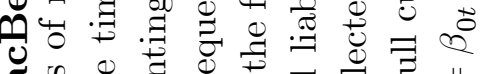

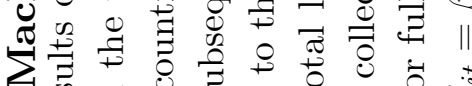

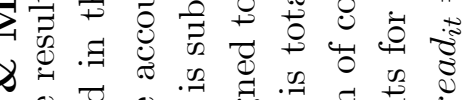
శ్

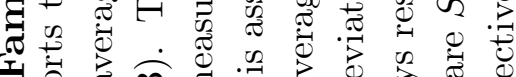

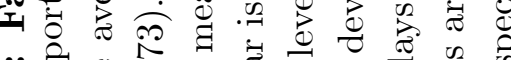

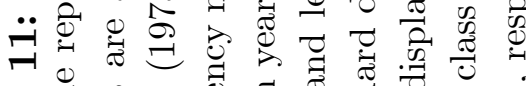

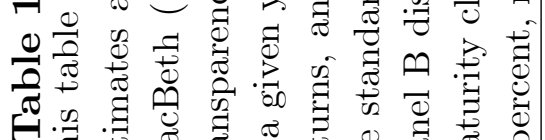

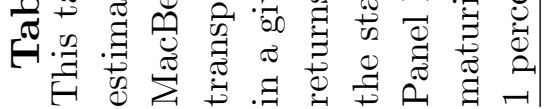

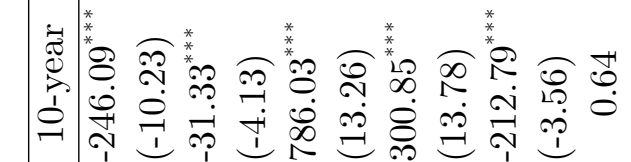

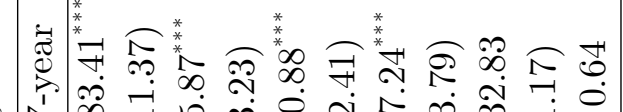

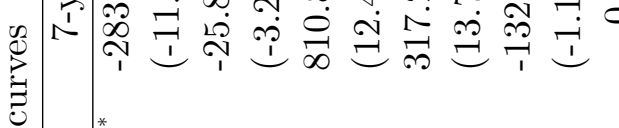

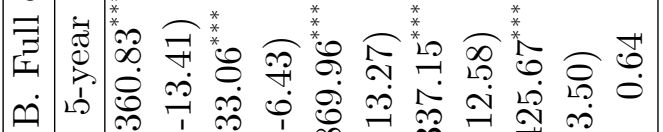

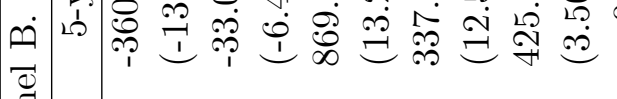
㱐

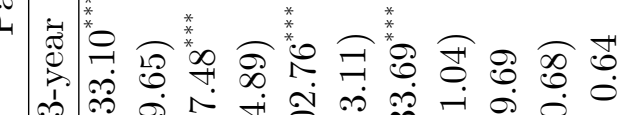

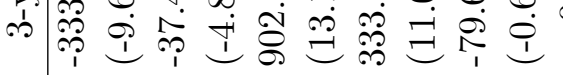

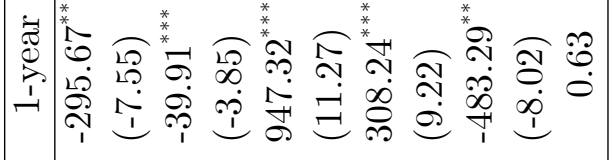

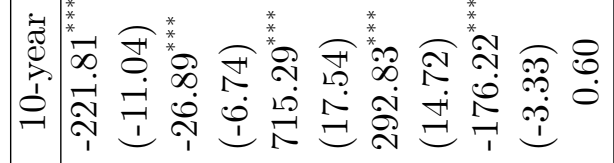

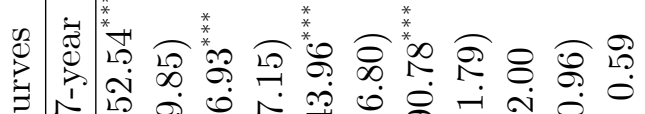

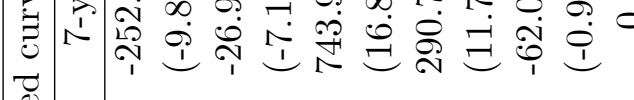

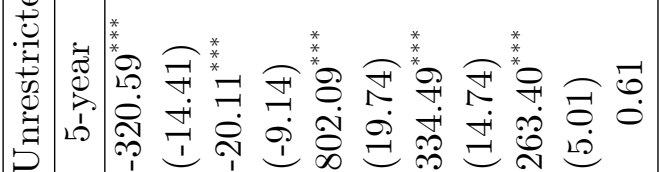

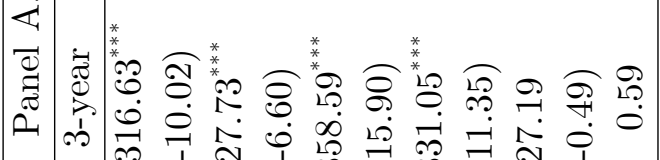

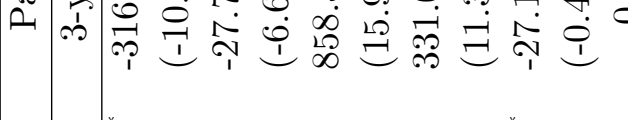

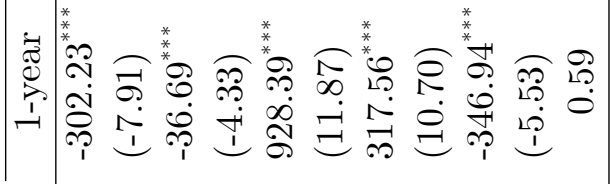

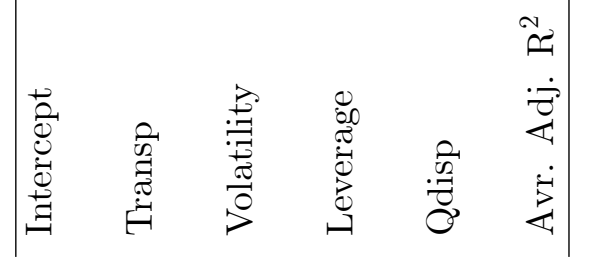




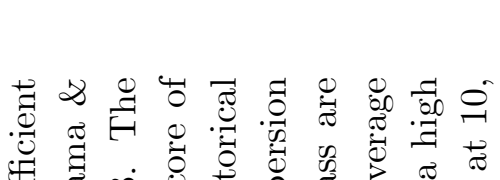

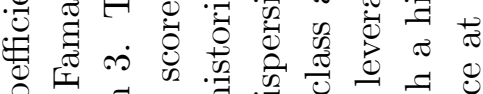

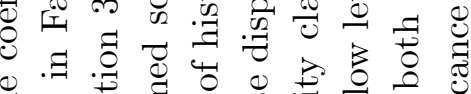

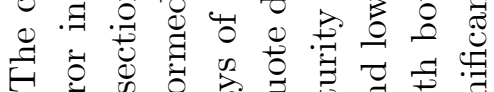
-

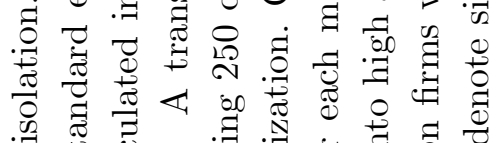
. g..$\exists$ क

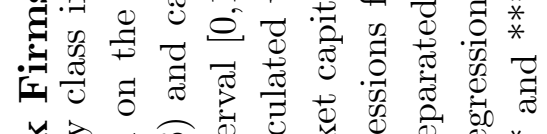

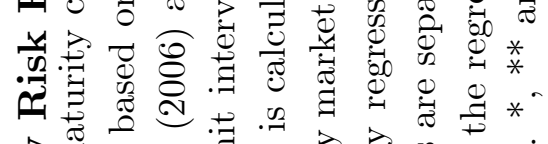

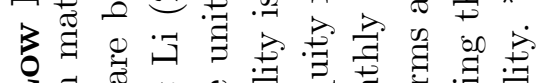

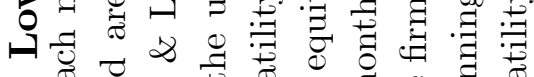

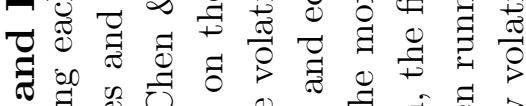

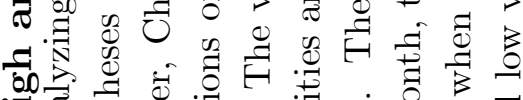

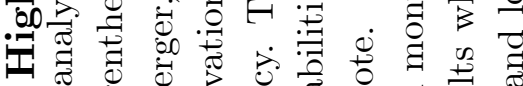
తే

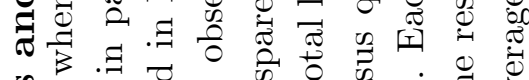

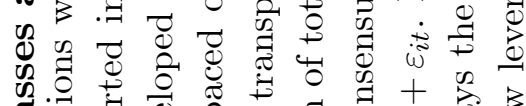

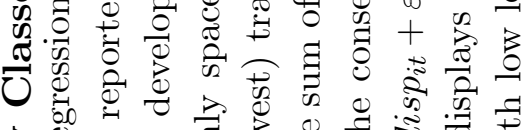

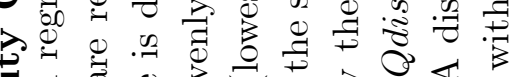

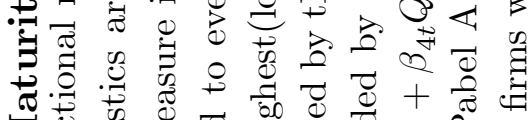

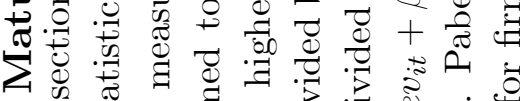

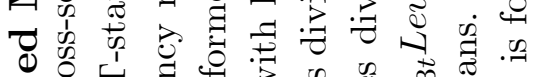

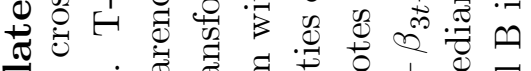
它

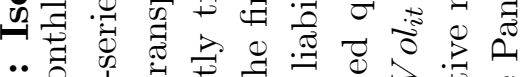
ஸี

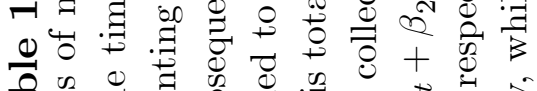

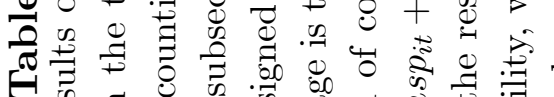

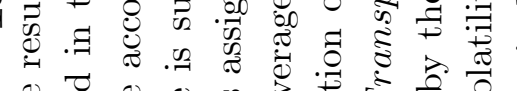

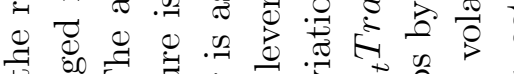

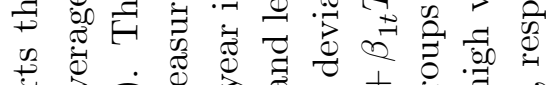

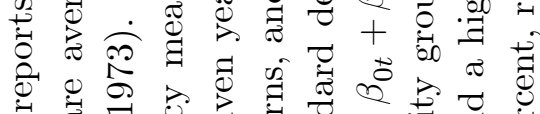

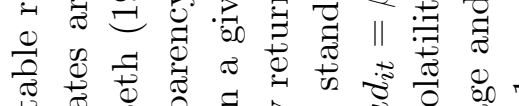

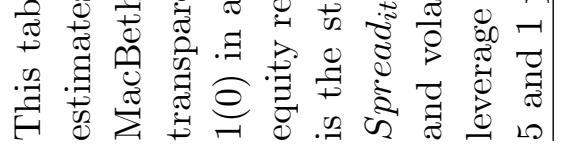

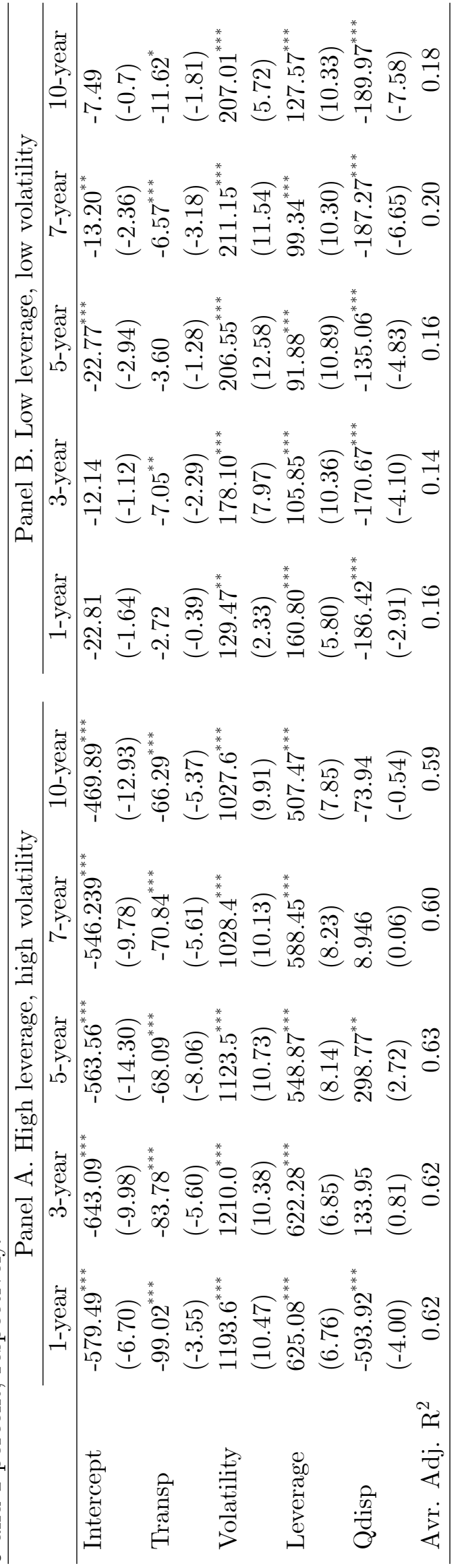




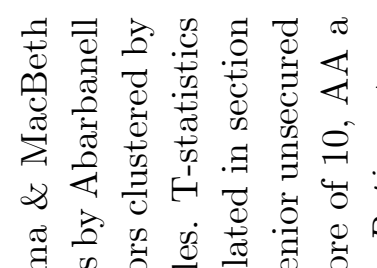

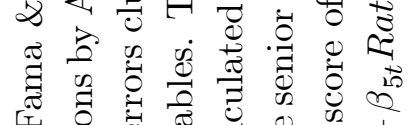
थ

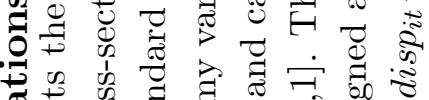

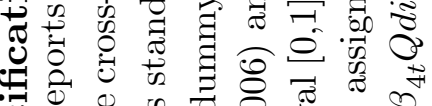

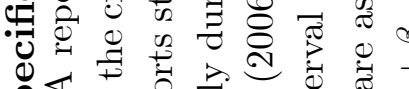

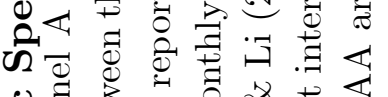

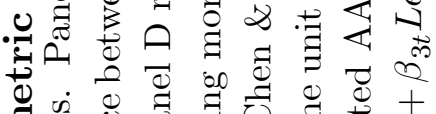
帛

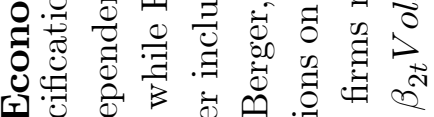

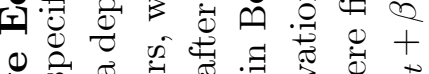

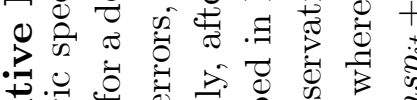

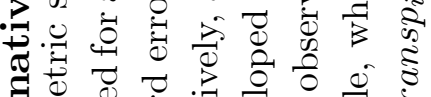

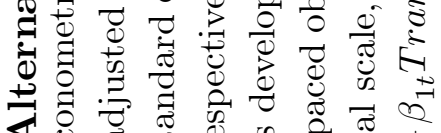
$0_{1}$
0
0

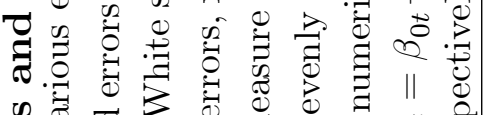

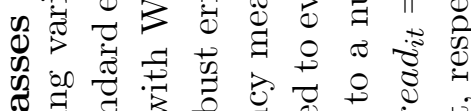

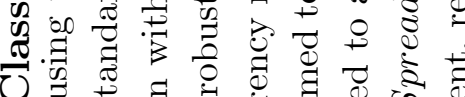

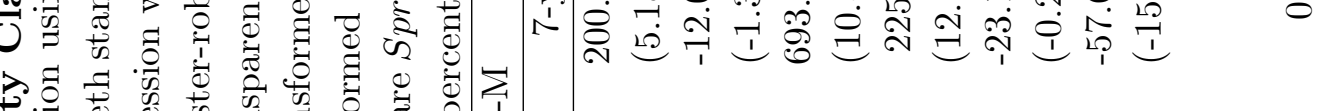

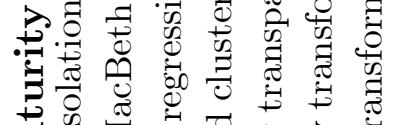

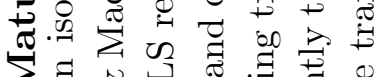

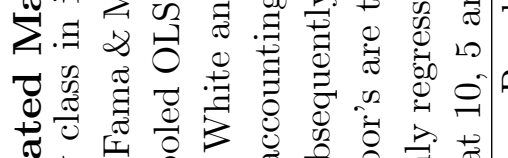
을 कon

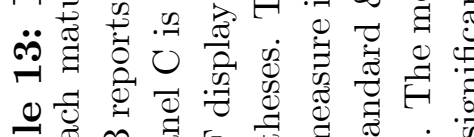

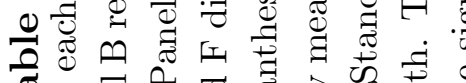

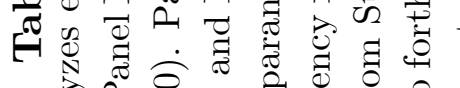

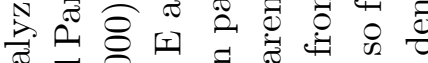

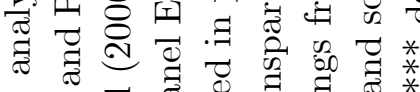

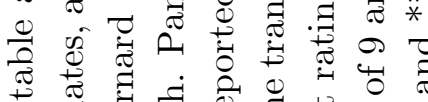

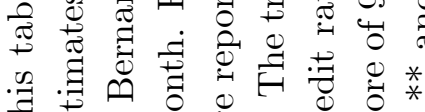

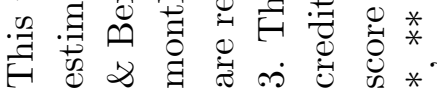

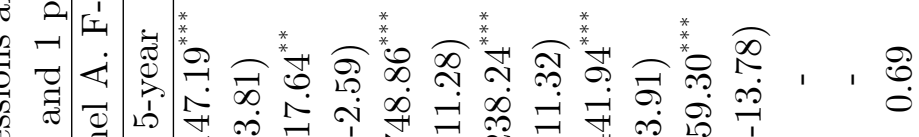

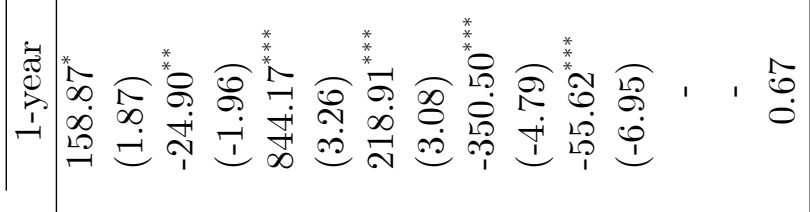

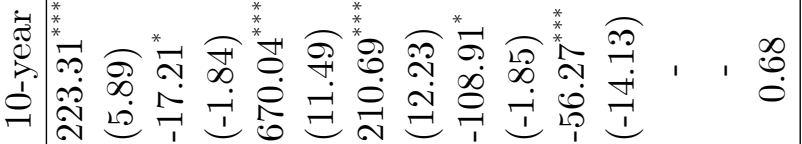

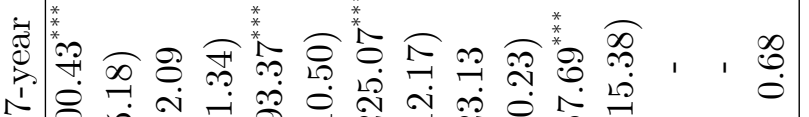

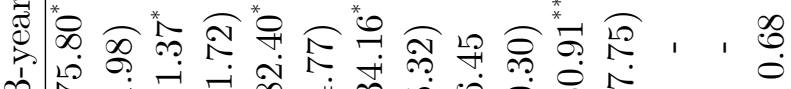

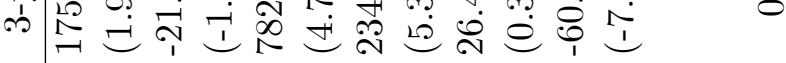

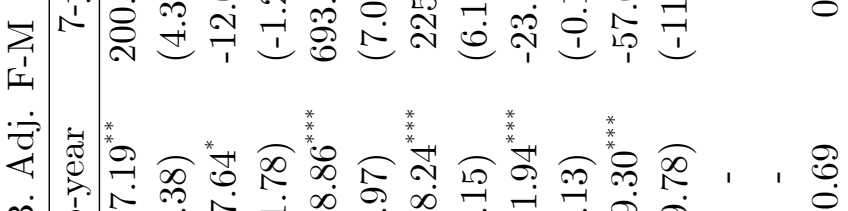

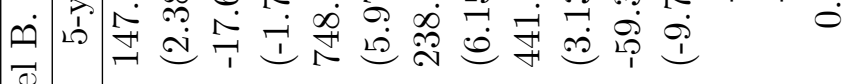
สี

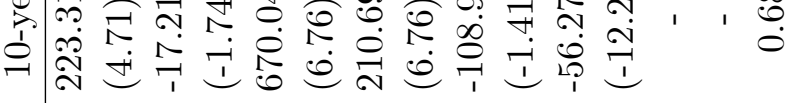

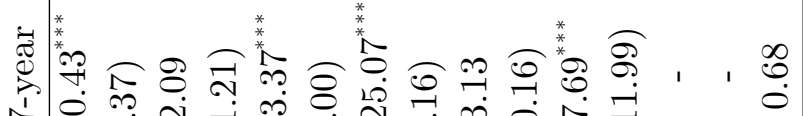




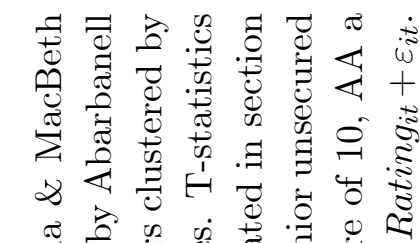

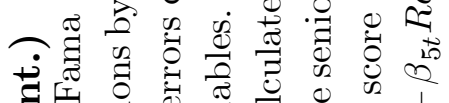

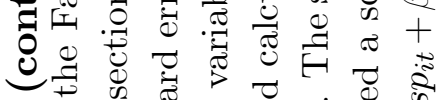

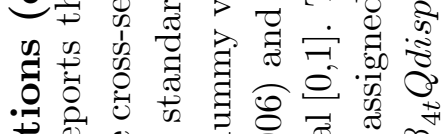

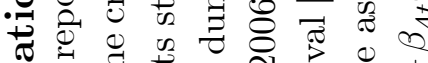

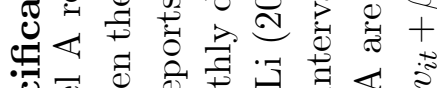

نृ

थम 0 व

ن

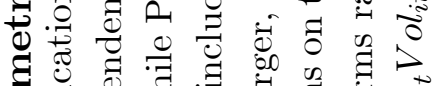

过矛过

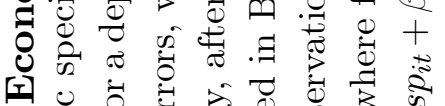

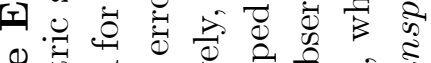

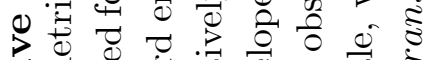

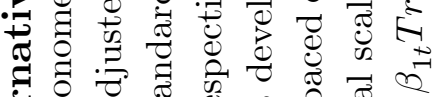

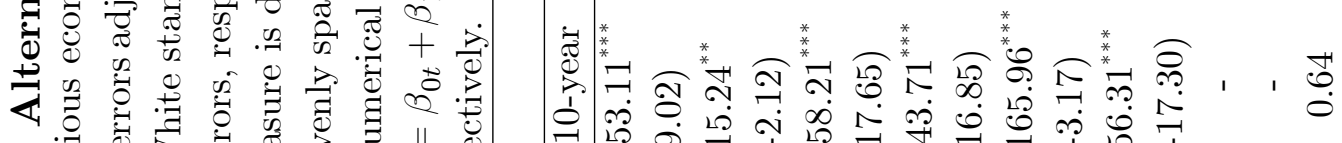
ठ

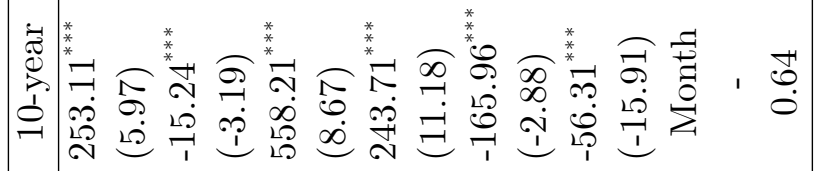

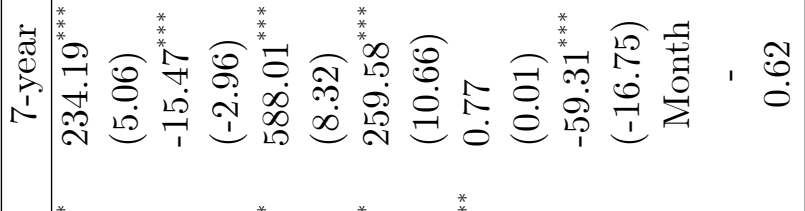

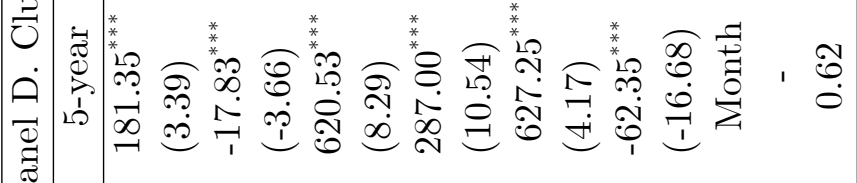
की

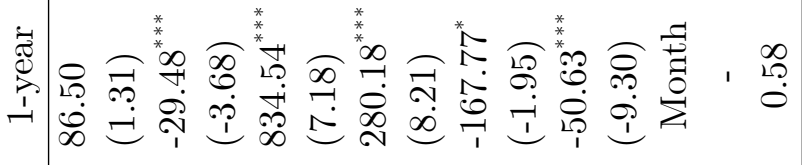
ส

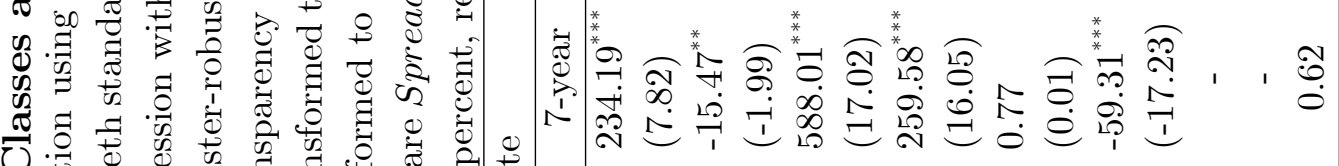

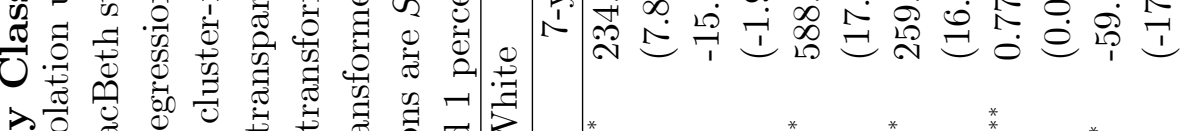

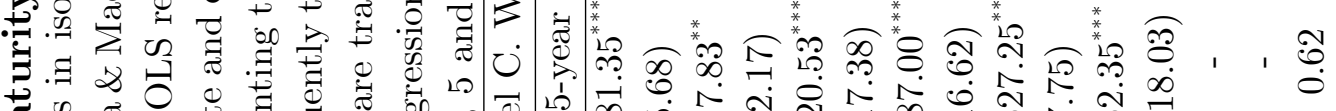

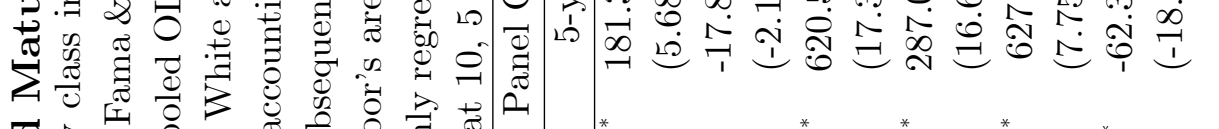

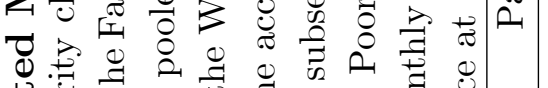

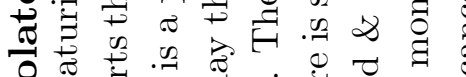

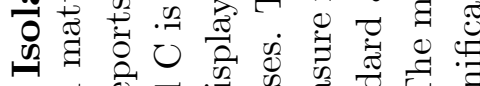

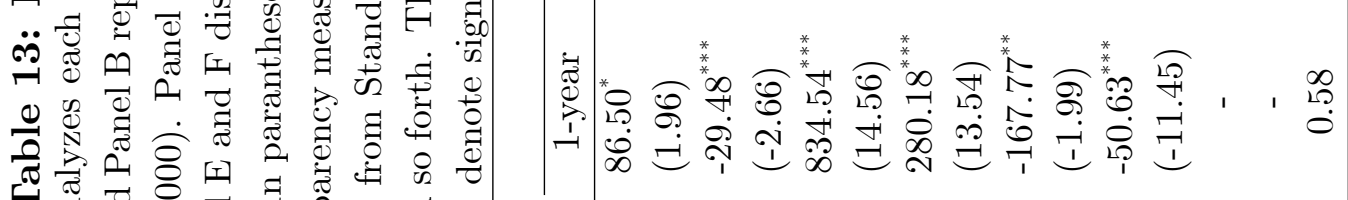

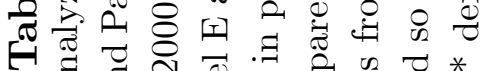

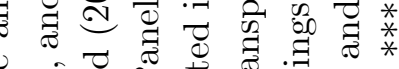

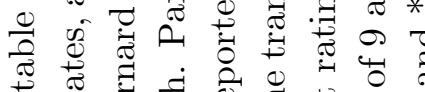

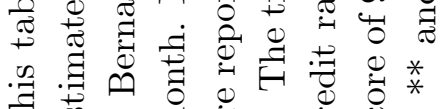

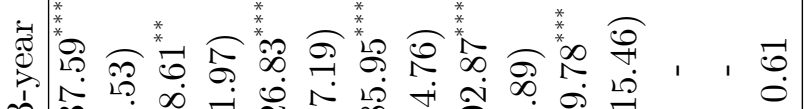
ค่

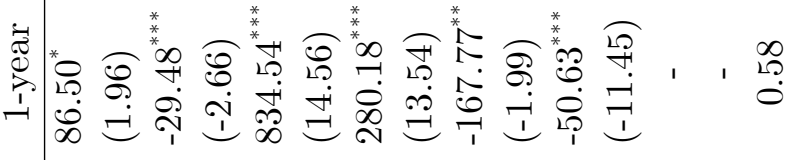

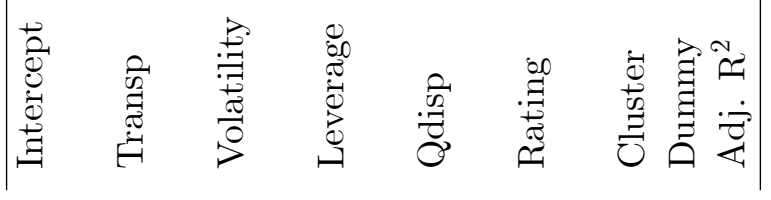




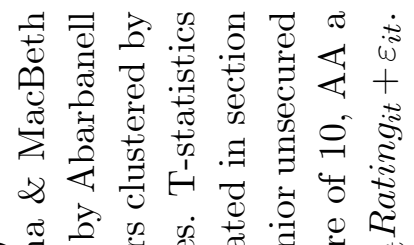

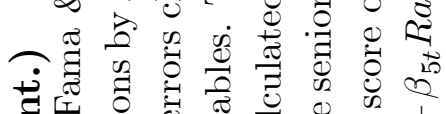

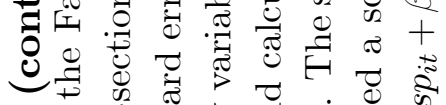

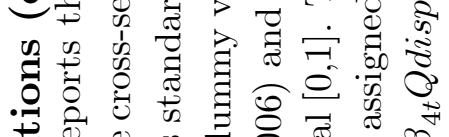

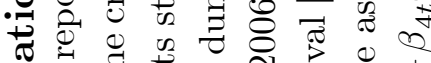

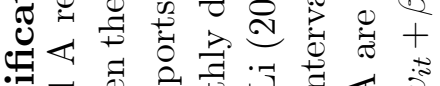

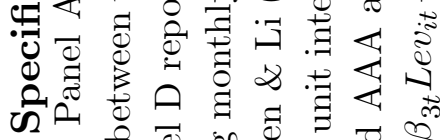

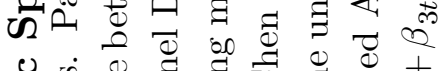

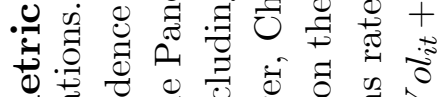

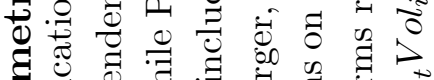

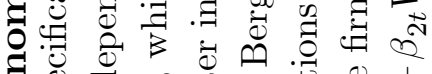

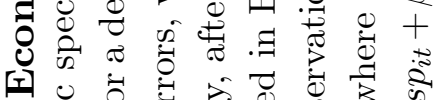

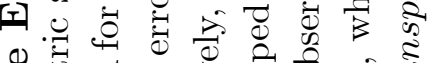

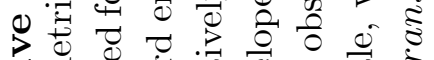

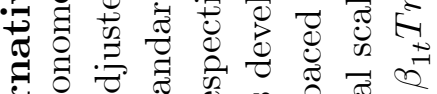

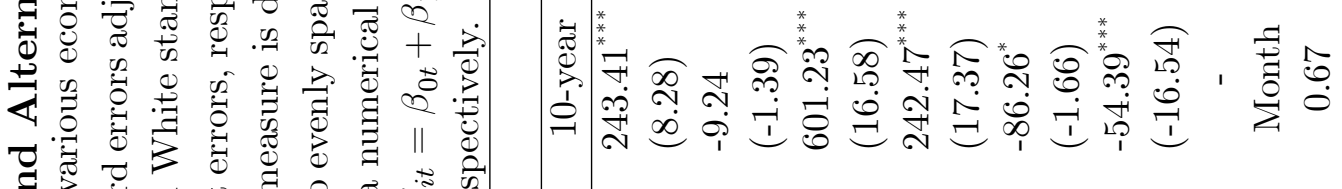

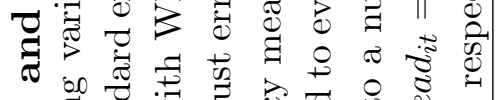

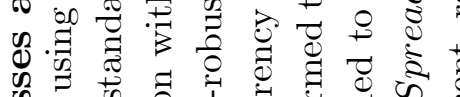

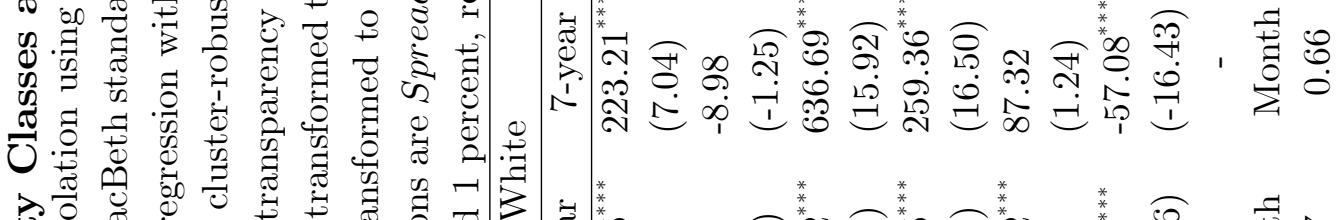

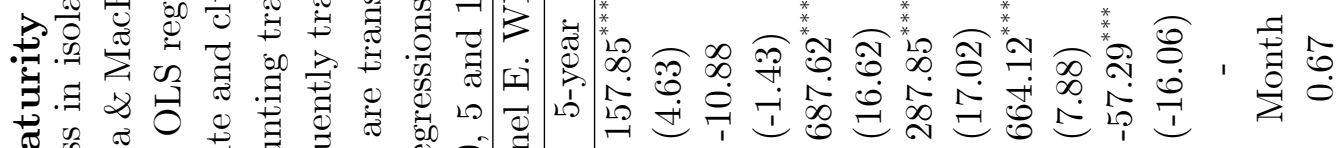

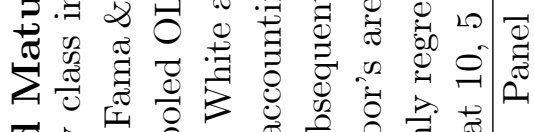

ग.

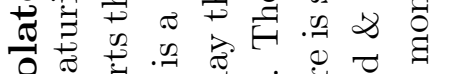

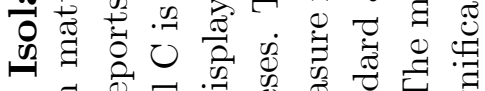
仓

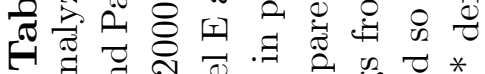
ส] 范㻤

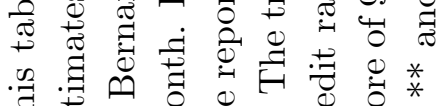

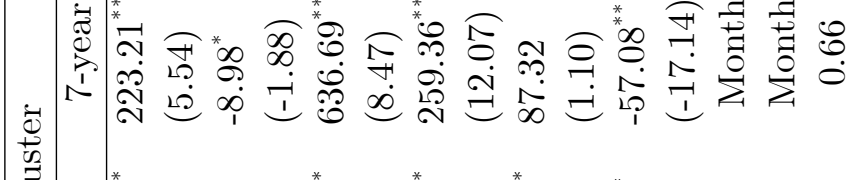

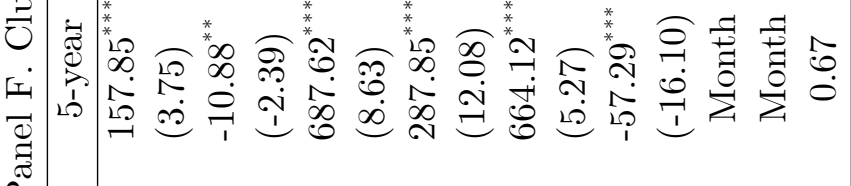

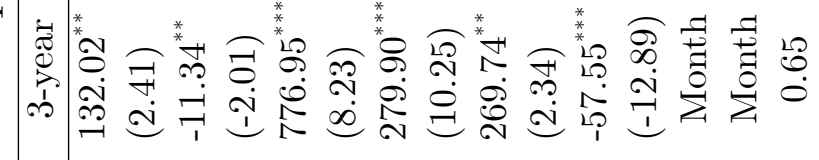

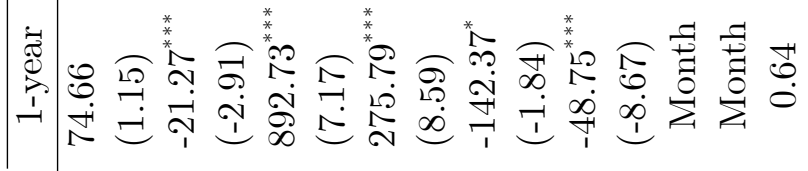

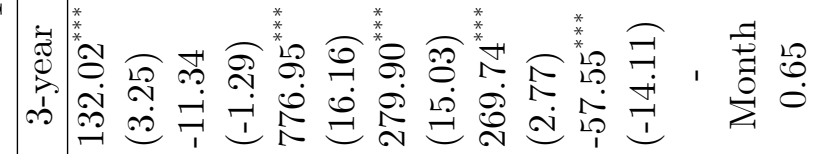

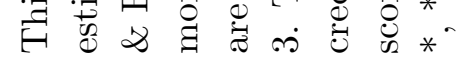

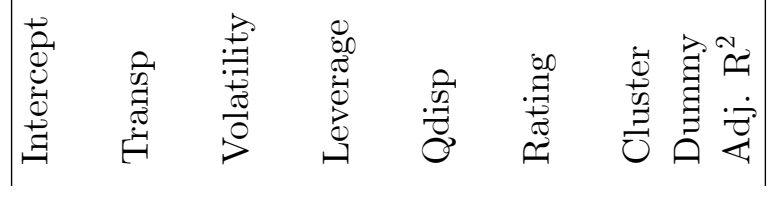


.

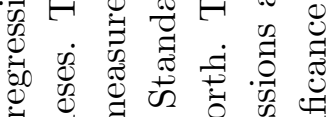
过

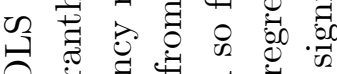

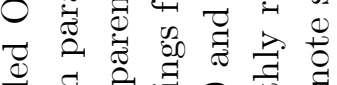
要. ๙

. .

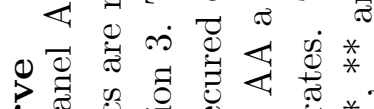

范 U.

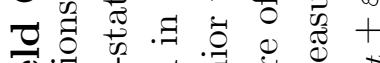
耐

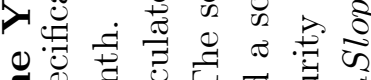
㐘 马. สี

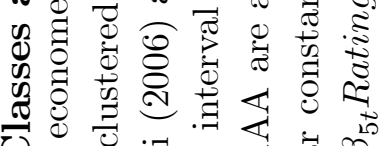

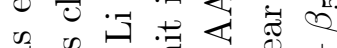
入.

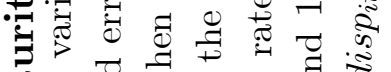
苛

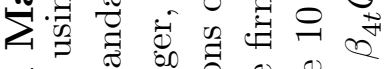

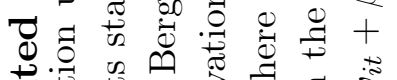

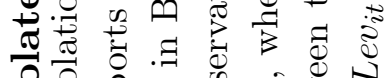
象.

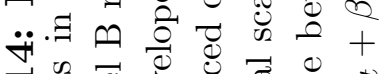

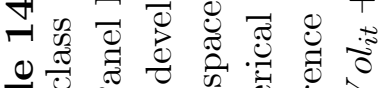

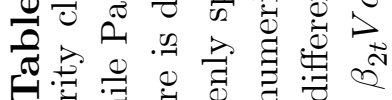

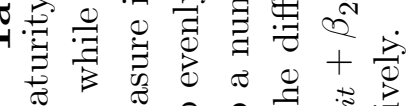

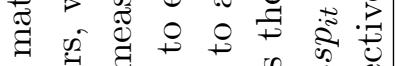

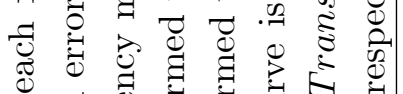
\%

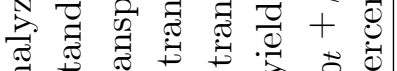
तै $5 D 000$ 0.

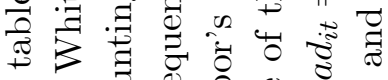

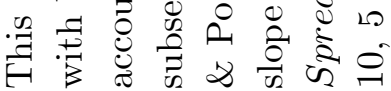

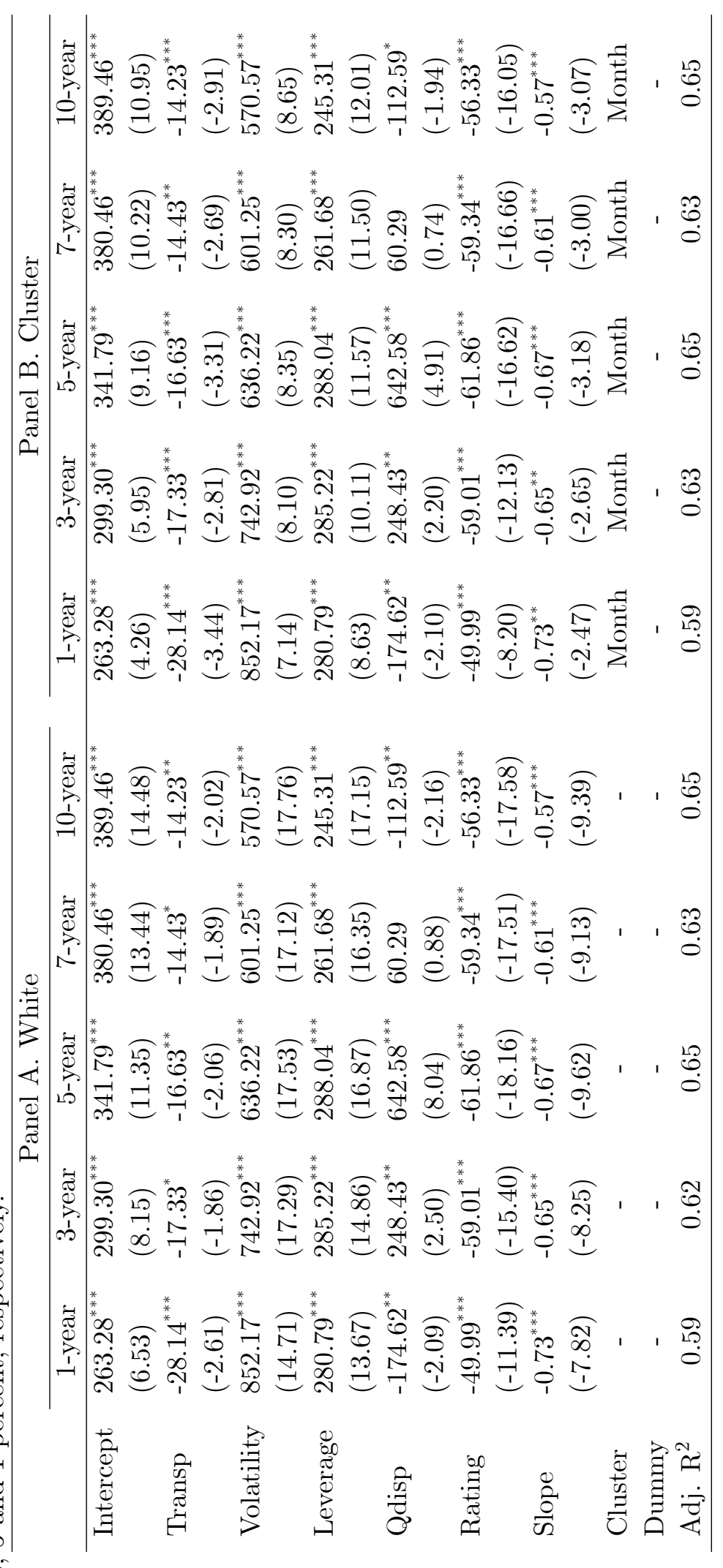




\section{Figure 1: Conditional Asset Density}

The figure illustrates the conditional asset density for varying accounting precisions, reproducing the base case in Duffie \& Lando (2001). The tax rate $\theta=0.35$, volatility $\sigma=0.05$, risk-free rate $r=0.06$, drift $m=0.01$, payout ratio $\delta=0.05$ and default cost $\alpha=0.3$. The coupon rate $C=8.00$ and the default barrier $V_{B}(C)=78$. A noise-free asset report $V(t-1)=\hat{V}(t-1)=86.3$ is assumed together with a current noisy asset report $\hat{V}(t)=86.3$. The standard deviation $a$ is assumed at $0.05,0.1$ and 0.25 and measures the degree of accounting noise.

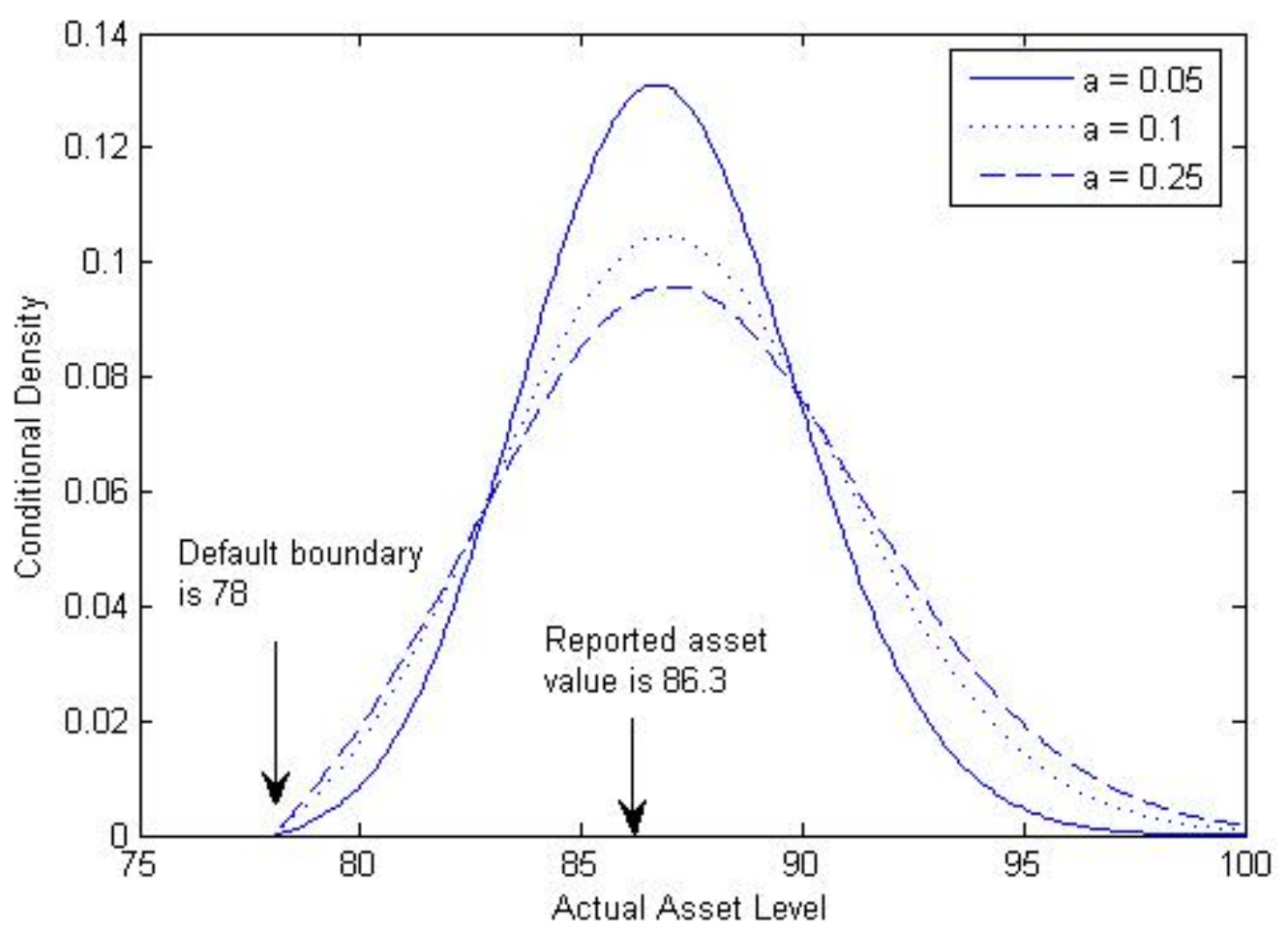




\section{Figure 2: CDS Spreads for Varying Accounting Precisions}

The figure illustrates the CDS spreads associated with the conditional asset densities for varying accounting precisions, reproducing the base case in Duffie \& Lando (2001). The tax rate $\theta=0.35$, volatility $\sigma=0.05$, risk-free rate $r=0.06$, drift $m=0.01$, payout ratio $\delta=0.05$, default cost $\alpha=0.3$ and recovery rate $R=0.5$. The coupon rate $C=8.00$ and the default barrier $V_{B}(C)=78$. A noise-free asset report $V(t-1)=\hat{V}(t-1)=86.3$ is assumed together with a current noisy asset report $\hat{V}(t)=86.3$. The standard deviation $a$ is assumed at $0.05,0.1$ and 0.25 and measures the degree of accounting noise.

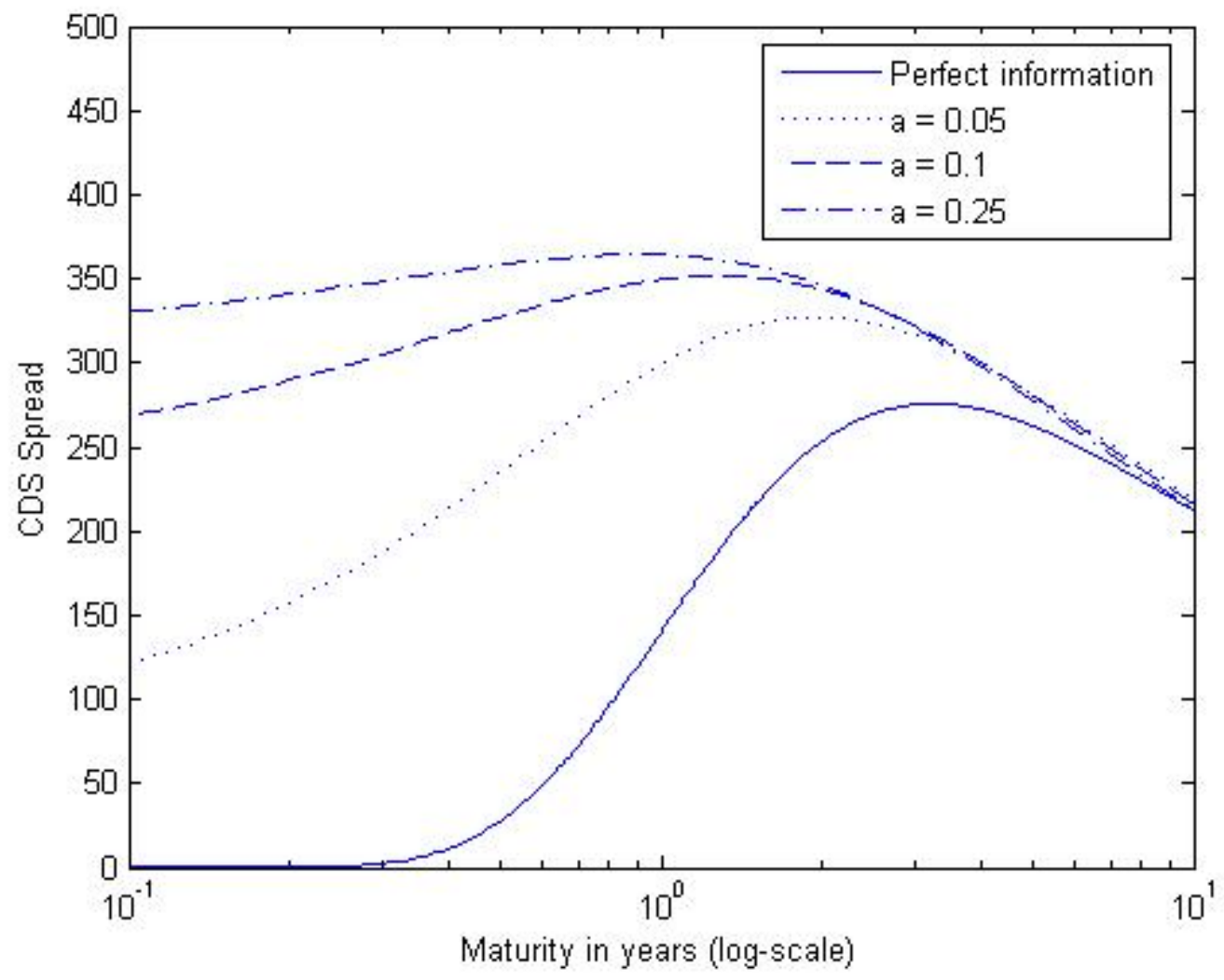




\section{Figure 3: CDS Spreads For a Low Leverage Firm}

The figure illustrates the CDS spreads for varying accounting precisions in Duffie \& Lando (2001). A higher current and lagged asset report are assumed, capturing a lower leverage ratio. The tax rate $\theta=0.35$, volatility $\sigma=0.05$, risk-free rate $r=0.06$, drift $m=0.01$, payout ratio $\delta=0.05$, default cost $\alpha=0.3$ and recovery rate $R=0.5$. The coupon rate $C=8.00$ and the default barrier $V_{B}(C)=78$. A noise-free asset report $V(t-1)=\hat{V}(t-1)=90.0$ is assumed together with a current noisy asset report $\hat{V}(t)=90.0$. The standard deviation $a$ is assumed at $0.05,0.1$ and 0.25 and measures the degree of accounting noise.

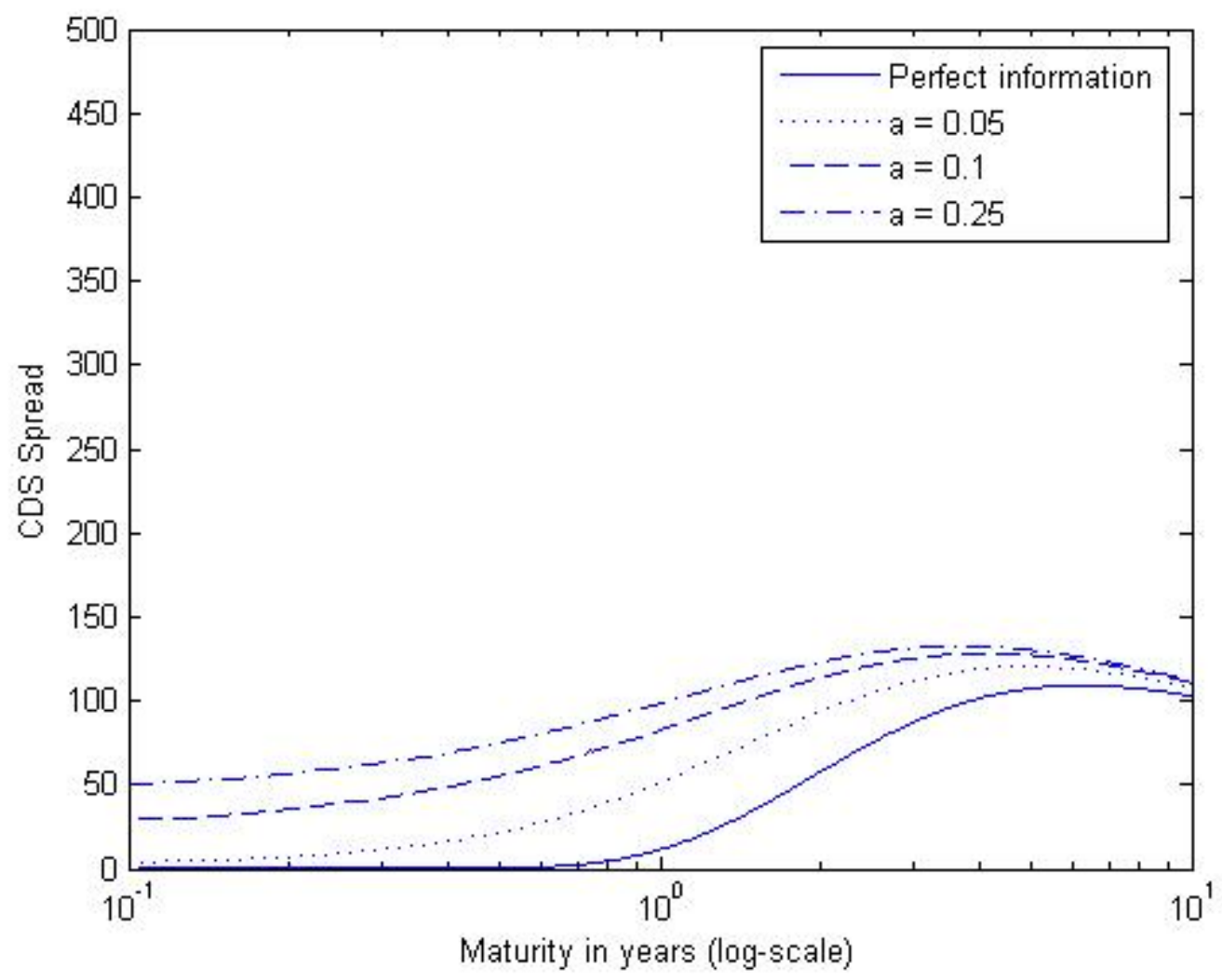




\section{Figure 4: CDS Spreads For a Low Volatility Firm}

The figure illustrates the CDS spreads for varying accounting precisions in Duffie \& Lando (2001) for a firm with low volatility. The tax rate $\theta=0.35$, volatility $\sigma=0.04$, risk-free rate $r=0.06$, drift $m=0.01$, payout ratio $\delta=0.05$, default cost $\alpha=0.3$ and recovery rate $R=0.5$. The coupon rate $C=8.00$ and the default barrier $V_{B}(C)=78$. A noise-free asset report $V(t-1)=\hat{V}(t-1)=86.3$ is assumed together with a current noisy asset report $\hat{V}(t)=86.3$. The standard deviation $a$ is assumed at $0.05,0.1$ and 0.25 and measures the degree of accounting noise.

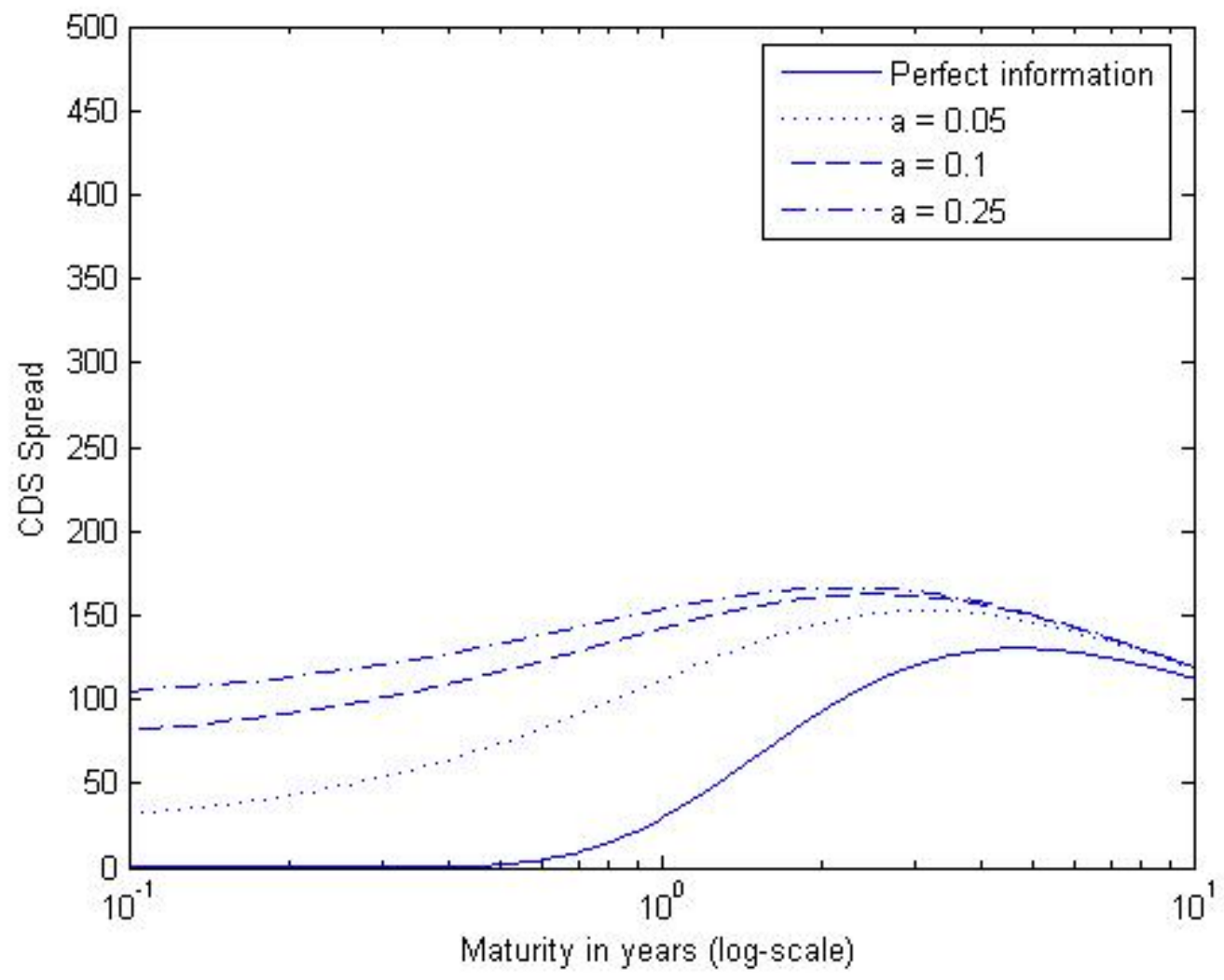


Figure 5: CDS Spreads For a Higher Initial Firm Level

The figure illustrates the CDS spreads for varying accounting precisions in Duffie \& Lando (2001). The current asset report is at it's base case level, while the lagged asset report is higher. The tax rate $\theta=0.35$, volatility $\sigma=0.05$, risk-free rate $r=0.06$, drift $m=0.01$, payout ratio $\delta=0.05$, default cost $\alpha=0.3$ and recovery rate $R=0.5$. The coupon rate $C=8.00$ and the default barrier $V_{B}(C)=78$. A noise-free asset report $V(t-1)=\hat{V}(t-1)=90.0$ is assumed together with a current noisy asset report $\hat{V}(t)=86.3$. The standard deviation $a$ is assumed at $0.05,0.1$ and 0.25 and measures the degree of accounting noise.

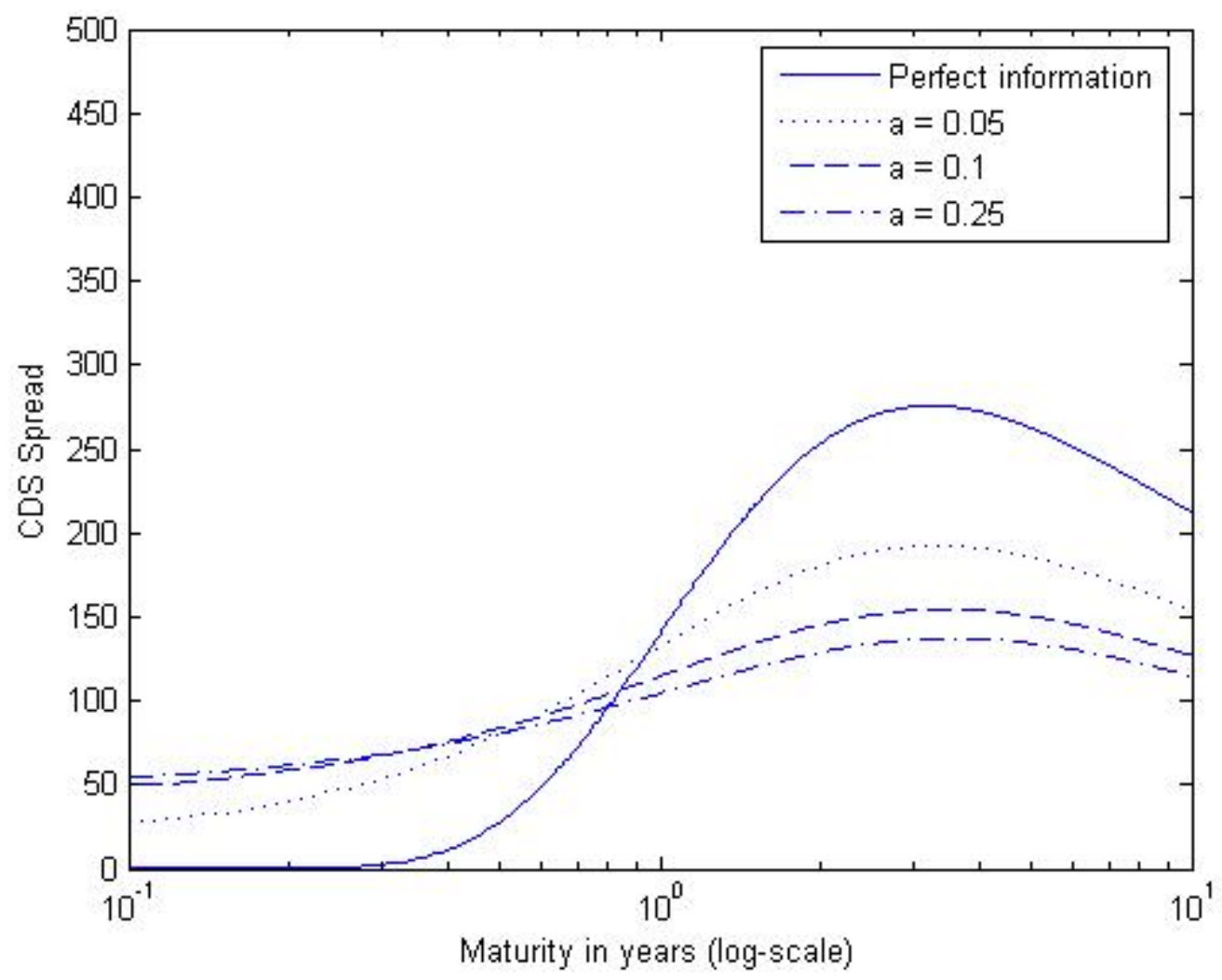

